\title{
Experimental study on fire resistance of precast concrete columns with efficient reinforcement
}

\author{
Haoming $\mathrm{Xu}^{\mathrm{a}}$, Min $\mathrm{Yu}^{\mathrm{a}, \mathrm{c},{ }^{*}}$, Congcong Xue ${ }^{\mathrm{a}}$, Lihua $\mathrm{Xu}^{\mathrm{a}}$, Jianqiao $\mathrm{Ye}^{\mathrm{b}, *}$ \\ a. School of Civil Engineering, Wuhan University, Wuhan 430072, China; \\ b. Department of Engineering, Lancaster University, Lancaster, LA1 4YR. UK; \\ c. Engineering Research Center of Urban Disasters Prevention and Fire Rescue Technology of Hubei Province, \\ Wuhan 430072, China;
}

\begin{abstract}
In order to improve installation efficiency, construction quality and reduce the cost of monolithic precast concrete frame structures, precast concrete columns reinforced by efficient reinforcement have been proposed in recent years. Their static and seismic behaviors generally meet design expectations, while, to the authors' best knowledge, their fire resistance has not been properly studied. In this paper, results from fire resistance experiments on full-scale precast concrete columns reinforced by efficient reinforcement under standard fire exposure conditions are presented. The effect of reinforcement forms, load intensity and fire conditions on the fire resistance of the precast concrete columns has been studied. The test results show that fire resistance of the connection zone of the precast concrete column is higher than that of the non-connection zone. The test results also show that precast concrete columns reinforced by cluster reinforcement have a higher fire resistance than columns reinforced by large-diameter reinforcement. On the basis of the test results and the calculation methods current in use, a simplified approach that considers the effect of cross-sectional area reduction and temperature difference caused by spalling is proposed to predict fire resistance of precast concrete columns reinforced by efficient reinforcement.
\end{abstract}

Keywords: Precast concrete columns; Efficient reinforcement; Cluster reinforcement; Large-diameter reinforcement; Rebar splicing by grout-filled coupling sleeve; Rebar lapping in grout-filled hole; Fire resistance

\section{Introduction}

Compared with the traditional cast-in-situ construction method, precast concrete construction has been increasingly used in the world due to its remarkable advantages of shortening construction period, stable and reliable quality, less resource consumption, less environmental impact and less labor-intensive. The monolithic precast concrete structures based on the design concept of emulating cast-in-place has been widely used in highrise buildings in seismic and non-seismic areas because of their enhanced integrity. However, the traditional approaches of reinforcing precast concrete components require dense reinforcement at connections, resulting in difficulties for arranging reinforcement in, e.g., beam-column joints, pouring and compacting concrete. Thus, the installation efficiency of the components is low and it is difficult to ensure the quality of installation. To address the above issues, some researchers proposed a "efficient reinforcement" ${ }^{\text {[1, 2] }}$ design concept for precast concrete components, by which large diameter $(d \geq 25 \mathrm{~mm})$ steel bars instead of medium diameter steel ones are arranged at the corner of a column section and jointed with grouted splice sleeve connections (see Fig. 1a). Alternatively, small diameter reinforcing bars are arranged in cluster at the corner of the column section with longitudinal rebar lapping in grout-filled ducts that are surrounded by confining spiral stirrups (see Fig. 1c). The design approaches were to reduce the number of longitudinal rebar joints and increase the spacing of longitudinal reinforcement. The approaches ultimately reduced the cost by improving the installation efficiency and construction quality of the monolithic precast concrete frame structures. An illustration of the above reinforcements is shown in Fig. 1. In order to promote the use of this new type of precast concrete columns in practical design, it is critically important to have a good understanding of its service performance under various 
disastrous loading conditions. In the past few years, extensive experimental studies have been carried out ${ }^{[1-4]}$. Preliminary research results have shown that the precast concrete columns reinforced by efficient reinforcement have good static and seismic performance at room temperature. However, investigations on their fire resistance are hardly found and are required urgently.

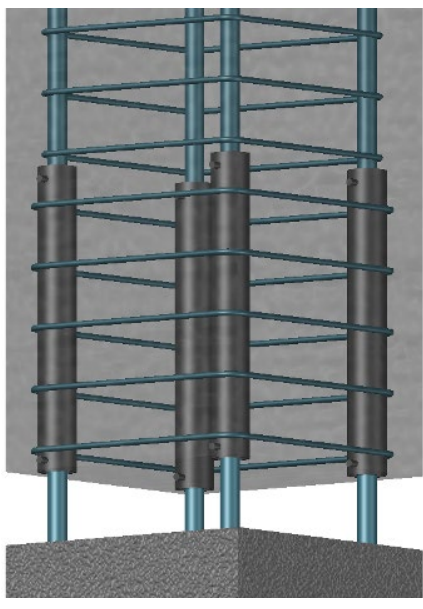

(a) Precast concrete column with largediameter rebars and sleeve grouting connections

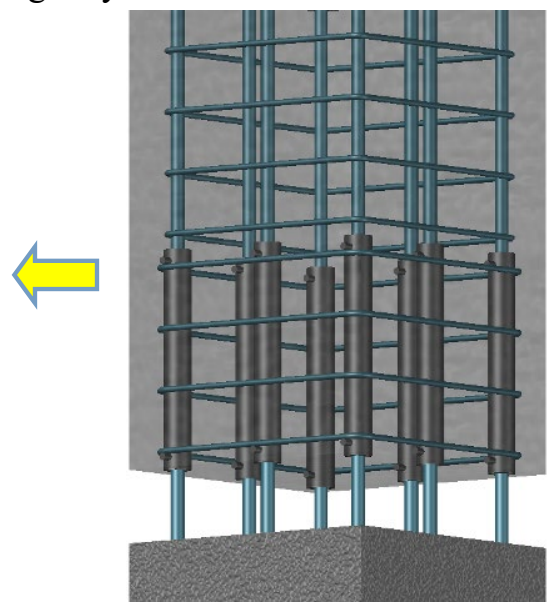

(b) Precast concrete column with normal reinforcement and sleeve grouting connections

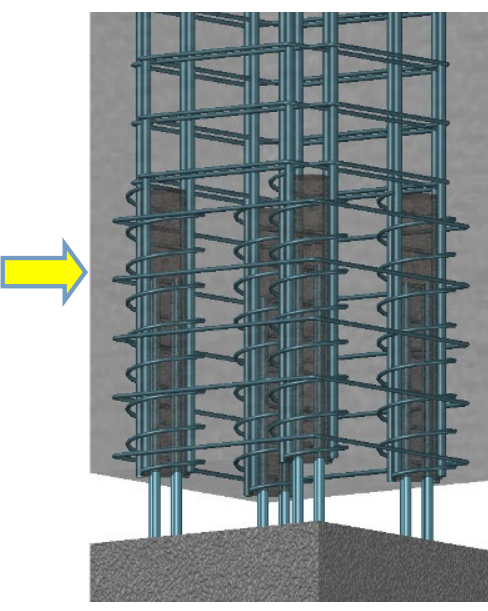

(c) Precast concrete column with cluster reinforcement and constrained grouting-anchor connections

Figure 1 Precast concrete columns with normal reinforcement and efficient reinforcement

Fire is one of the most common, dangerous and destructive disasters among many other disasters that endanger engineering structures. Fire can easily cause material deterioration, component damage, structural failure and even collapse. As the main load bearing components of a building structure, the performance of columns under fire has a significant impact on the fire safety of the whole building. Therefore, the study of fire resistance of columns is very important. In the past decades, researchers have carried out many experimental studies on the fire resistance of reinforced concrete columns, e.g., the work by Lie ${ }^{[5]}$, Dotreppe ${ }^{[6]}$, Kodur $^{[7-9]}$, $\mathrm{Ali}^{[10,11]}, \mathrm{Wu}^{[12-14]}, \operatorname{Tan}^{[15,16]}$, Rodrigues ${ }^{[17]}$, Shah ${ }^{[18]}, \mathrm{Rush}^{[19]}$, and Buch ${ }^{[20]}$. Previous experimental studies suggested that the load ratio, cross-section dimensions, slenderness ratio, concrete strength, aggregate type, longitudinal reinforcement ratio, confining reinforcement, eccentricity and fire scenario were the main parameters that influence fire resistance of reinforced concrete columns. Dotreppe et al. ${ }^{[6]}$ conducted extensive parametric studies on the fire resistance of reinforced concrete columns with normal reinforcement through experiments. The results showed that columns with reinforcing bars of large diameter $(25 \mathrm{~mm})$ had led to fire resistances appreciably smaller than the expected. Such unfavorable results have not been observed when reinforcing bars of 12 and $16 \mathrm{~mm}$ in diameter were used. Additional tests on columns having large diameter reinforcing bars were required to understand the influence of the diameter on the performance of the columns. Similarly, Martins et al. ${ }^{[21]}$ have experimentally determined that the use of a large diameter $(25 \mathrm{~mm})$ for reinforcing bars could counteract the beneficial effect on the fire resistance provided by increasing the reinforcement ratio. Park et al. ${ }^{[22]}$ studied the influence of some parameters on temperature distributions and spalling of high strength concrete (HSC) columns under fire through experiments. The results show that with the same reinforcement ratio and ambient temperature, the temperature within the column is higher and spalling of the HSC columns is more likely to occur if the diameter of the distributed reinforcing bars is smaller. Kodur et al. ${ }^{[7]}$ and Raut et al. ${ }^{[23]}$ tested the fire resistance of HSC columns. Their results show that the fire resistance of HSC columns is lower than that of normal strength concrete columns because of severe spalling of high strength concrete under fire. The provision of cross ties and closer tie spacing has a significant beneficial effect on the fire resistance of HSC columns.

However, most of the experimental studies were carried out on cast-in-situ reinforced concrete columns that normally had smaller cross-sections and reinforcing rebar diameter $(<25 \mathrm{~mm})$, which failed to consider the 
complex mechanical properties of the connection zone under elevated temperature. At present, to the authors' best knowledge, experimental studies on the behavior of grouted sleeve connection at elevated temperatures are very limited ${ }^{[24,25]}$, and the study on constrained grouting-anchor connections at elevated temperatures has not been reported. Moreover, most of the experimental studies have been carried out on the performance of steel bar connections subjected to uniformly elevated temperature, which cannot represent the real state of stresses of the steel bar connections in the precast concrete columns. Due to the structural complexity of the connections of a column, where considerable proportion of high-strength grouting materials are injected into and the thickness of concrete cover of grouting sleeve is much smaller than that of the longitudinal reinforcements, fire resistance tests are required to assess the likelihood of failure occurring in the zone.

Based on the past standard fire tests, fire resistance ratings of reinforced concrete columns, which are usually based on the dimensions of the columns and the cover of the reinforcement, have been documented in various building codes. In addition, some of the $\operatorname{codes}^{[26,27]}$ and published research ${ }^{[18,28,29]}$ have provided simple calculation methods for estimating fire resistance of reinforced concrete columns. Although these calculation methods consider many factors, they do not take into account the impact of efficient reinforcement and the influence of grouting connections of a precast concrete column. Thus, whether they can be applied to precast concrete columns reinforced by efficient reinforcement with confidence remains to be studied. In view of the above discussions, an experimental study on full scale precast concrete columns reinforced by efficient reinforcement under standard fire exposure conditions is reported in this paper. The test variables include reinforcement forms, load intensity and fire conditions. Data from the tests are utilized next to study the fire response of precast concrete columns reinforced by efficient reinforcement, i.e., by studying the spalling and failure modes, thermal responses, structural responses and fire resistance of the columns. Fire resistance calculated from the design formulas currently in use for reinforced concrete columns are compared with the new test results to evaluate the applicability of the existing approaches to precast concrete columns reinforced by efficient reinforcement. Finally, based on Eurocode 2, a simplified approach considering concrete spalling for calculating fire resistance of precast concrete columns reinforced by efficient reinforcement is proposed and validated by the experimental data.

\section{Experimental study on fire resistance of precast concrete columns}

\subsection{Description of the specimens}

The experimental program consists of conducting fire resistance tests on six precast concrete columns with efficient reinforcement. The research parameters include the forms of efficient reinforcement, the design load ratio and the locations of fire exposure, as shown in Table 1, where the fire on column C-B and D-B are extended well above the connection zone, while the fire on column C-M and D-M are localized in the vicinity of the connection zones, as indicated by the red vertical lines (Fig. 2). The design load ratio of the columns is defined as the ratio of the actual applied load to the bearing capacity calculated according to the Chinese Design Codes [30] (GB 50010-2010). 
Table 1 Main parameters of the tested columns

\begin{tabular}{|c|c|c|c|c|c|c|c|c|}
\hline \multirow{2}{*}{$\begin{array}{l}\text { Efficient } \\
\text { reinforcement } \\
\text { forms }\end{array}$} & \multirow[b]{2}{*}{$\begin{array}{l}\text { Column } \\
\text { reference }\end{array}$} & \multicolumn{3}{|c|}{ Longitudinal steel bars } & \multirow[b]{2}{*}{$\begin{array}{c}\text { Design } \\
\text { (Actual) load } \\
\text { ratio } \mu\end{array}$} & \multirow[b]{2}{*}{$\begin{array}{l}\text { Test load } \\
\quad(\mathrm{kN})\end{array}$} & \multirow[b]{2}{*}{$\begin{array}{c}\text { Fire exposure } \\
\text { location }\end{array}$} & \multirow[b]{2}{*}{$\begin{array}{c}\text { Fire } \\
\text { resistance } \\
(\min )\end{array}$} \\
\hline & & $\begin{array}{c}\text { Number and } \\
\text { diameter }(\mathrm{mm})\end{array}$ & $\begin{array}{c}\text { Reinforcement } \\
\text { ratio }\end{array}$ & $\begin{array}{c}\text { Concrete } \\
\text { cover }(\mathrm{mm})\end{array}$ & & & & \\
\hline \multirow[t]{3}{*}{$\begin{array}{c}\text { Cluster } \\
\text { reinforcement }\end{array}$} & $\mathrm{C}-\mathrm{B} 1$ & $16 \subset 14$ & $1.54 \%$ & 30 & $0.70(0.40)$ & 2447 & Extended & 124 \\
\hline & $\mathrm{C}-\mathrm{B} 2$ & ${ }_{16} C_{14}$ & $1.54 \%$ & 30 & $0.57(0.32)$ & 1986 & Extended & 172 \\
\hline & C-M & ${ }_{16} C_{14}$ & $1.54 \%$ & 30 & $0.70(0.40)$ & 2484 & Local & $>133$ \\
\hline \multirow[t]{3}{*}{$\begin{array}{l}\text { Large-diameter } \\
\text { reinforcement }\end{array}$} & D-B1 & $4 C 28$ & $1.54 \%$ & 50 & $0.70(0.41)$ & 2447 & Extended & 91 \\
\hline & D-B2 & $4 C 28$ & $1.54 \%$ & 50 & $0.57(0.33)$ & 1986 & Extended & 140 \\
\hline & D-M & $4 C_{28}$ & $1.54 \%$ & 50 & $0.70(0.41)$ & 2484 & Local & 145 \\
\hline
\end{tabular}

All the test specimens have identical geometry of a nominal height $3.84 \mathrm{~m}$ and a $400 \mathrm{~mm} \times 400 \mathrm{~mm}$ crosssection (Fig. 2). There are two parts of the columns, i.e., Part A and Part B (Figs. 2 3). Part A is the precast concrete columns to be tested. Part B provides support to Part A through the anchorage bars as shown in Fig. 2(a) and (b), respectively, which are used to simulate beam-column joints in practical engineering design. The length of Part B is designed to be $1400 \mathrm{~mm}$ for the local fire exposure scenario, which is mainly for the convenience of observing the failure process of the connection zone in the fire test. In order to facilitate the installation and loading of the specimens, steel plates of $600 \mathrm{~mm} \times 560 \mathrm{~mm} \times 10 \mathrm{~mm}$ are welded at both ends of the specimens.

The selection of connections was influenced by the form of efficient reinforcement. A new type of groutinganchor connection was adopted for cluster reinforcement in the columns, and spiral stirrups were used to enhance the performance of the connections (Figs. 1 2). The heights of the connection zone of the columns with cluster reinforcement and large-diameter reinforcing rebar were $480 \mathrm{~mm}$ and $500 \mathrm{~mm}$, respectively. The concrete cover of the grouting sleeves was $33 \mathrm{~mm}$, resulting in a concrete cover of $50 \mathrm{~mm}$ for the longitudinal reinforcement. The average distance from the centers of steel bars to the nearest fire-exposed surface was $64 \mathrm{~mm}$ for all the columns. For the columns reinforced with large-diameter steel bars, the axis distance to the nearest fire-exposed surface was $64 \mathrm{~mm}$ (Fig. 2(g)), and for the columns reinforced with cluster steel bars, the axis distances of the individual bars to the nearest fire exposed surfaces were either 37 or $90 \mathrm{~mm}$ (Fig. 2(e)).

Type-K thermocouples of $3 \mathrm{~mm}$ thick were installed at the middle height of the connection zone and the precast columns to measure the temperature of the steel bars and the concrete. Detailed arrangement and numbering system of the thermocouples are shown in Fig. 2(e) (h). 


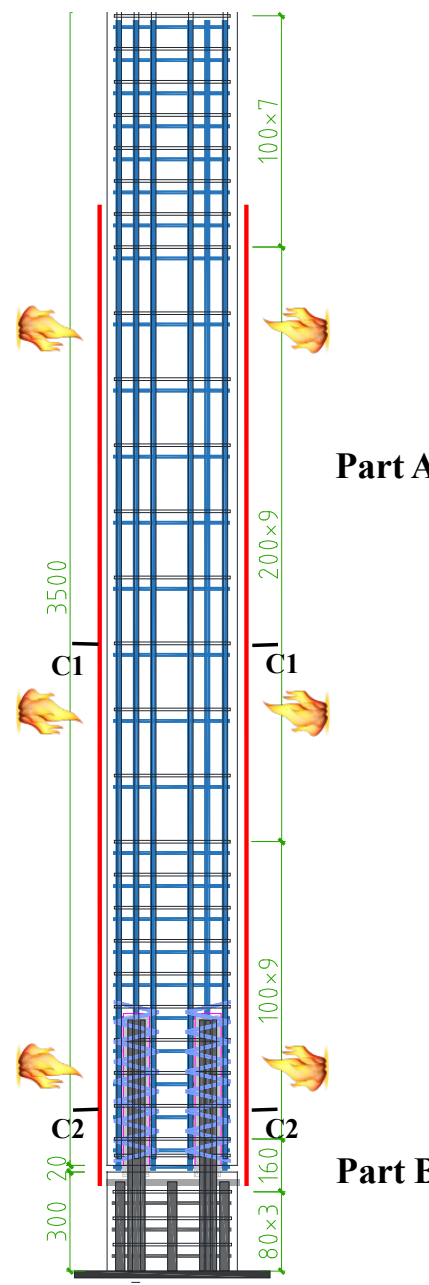

(a) Column C-B

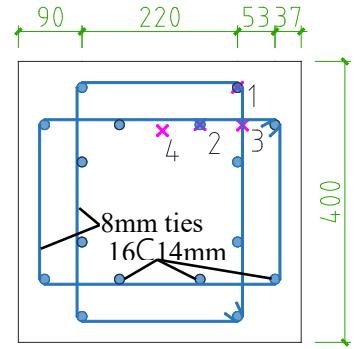

(e) C1-C1 section

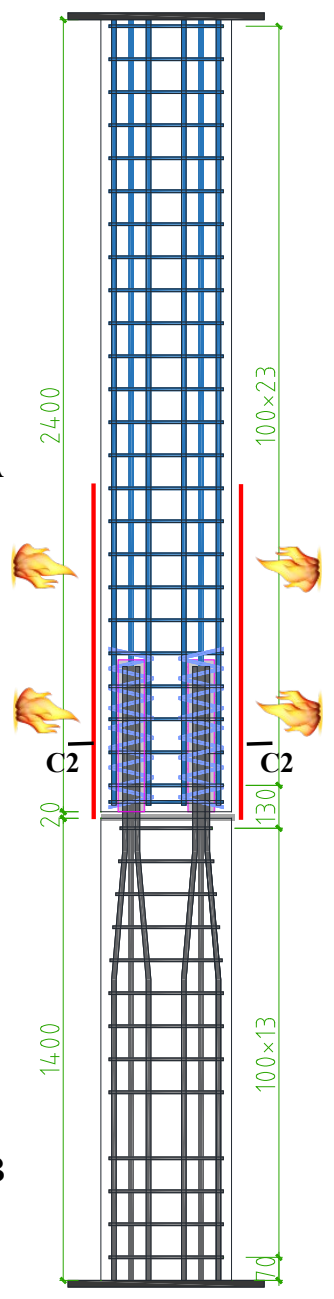

(b) Column C-M

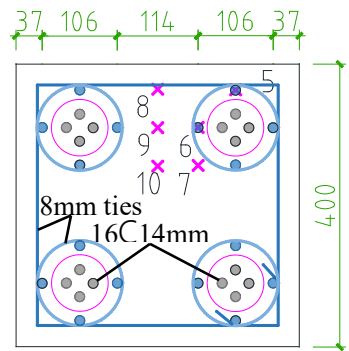

(f) $\mathrm{C} 2-\mathrm{C} 2$ section

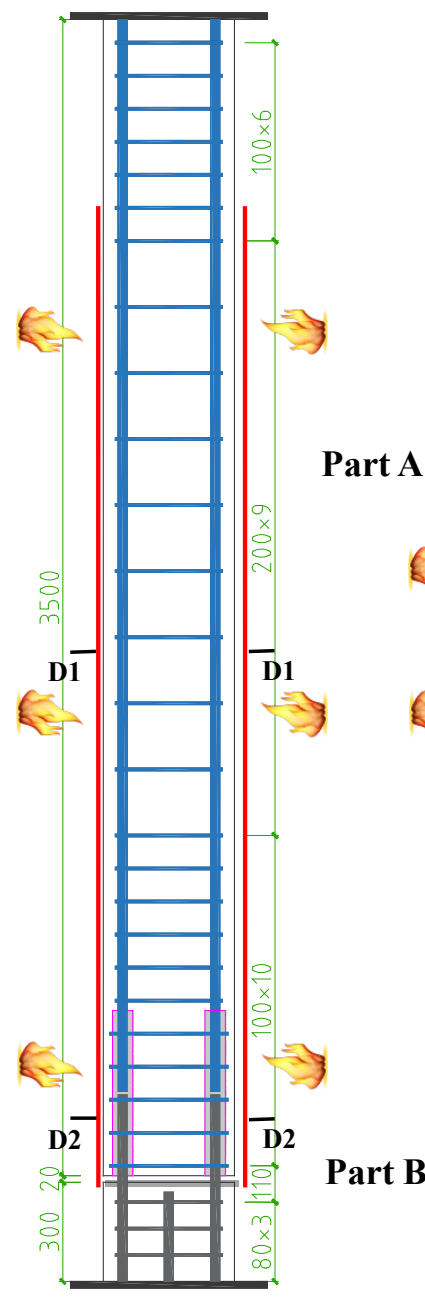

(c) Column D-B

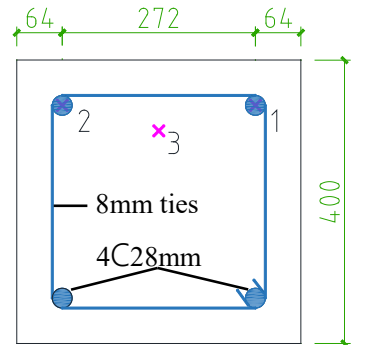

(g) D1-D1 section

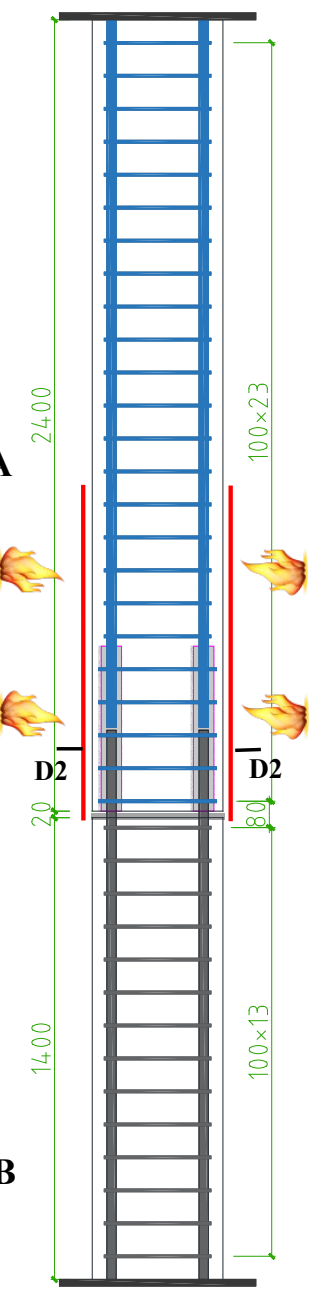

(d) Column D-M

Figure 2 The elevation, cross-section details and thermocouple arrangement of the specimens $(\mathrm{mm})$

\subsection{Specimen preparation}

The reinforcement cages of Part A were tied firstly as designed. The steel cages were then accurately positioned in the formwork and the end plates were welded (Fig. 3(a) (b)). Four $80 \mathrm{~mm}$ diameter steel tubes were temporally installed longitudinally to form four pockets at the positions to provide entries of the starter bars of Part B (Fig. 3(a)). The tubes were removed after completion of concrete casting. For the joints with large diameter steel reinforcement, four grouting sleeves were installed to the lower end of Part A (Fig. 3(b)). Two grouting holes were reserved by embedding two steel tubes of diameter $20 \mathrm{~mm}$ at the upper and lower ends of the reserved pockets or grouting sleeve. Finally, thermocouples were installed (Fig. 3(c)) before casting concrete. 


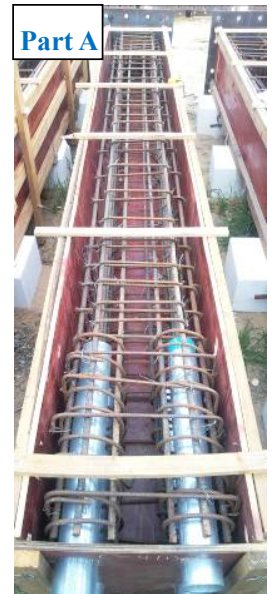

(a) Reinforcement cage and anchorage rebars of column C-B

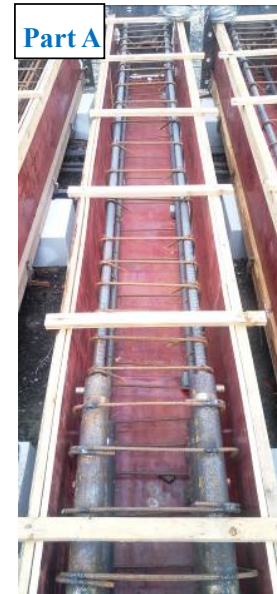

(b) Reinforcement cage and anchorage rebars of column D-B
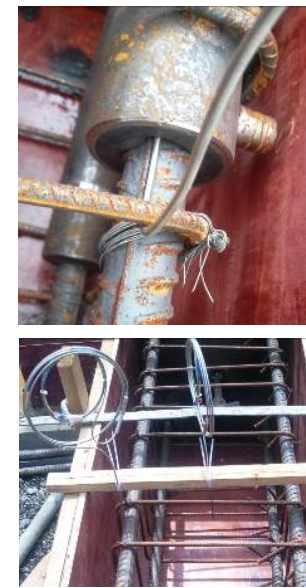

(c) Thermocouples installation

Figure 3 Construction of the columns

After concrete casting, the concrete was cured for 15 days before assembling the parts. The assembly process is as follows: (a) The contact surfaces of both Parts A and B were treated to enhance their connection performance (Fig. 4(a)). (b) The starter bars of Part B were inserted into the respective reserved pockets or grouting sleeves in Part A of the precast column (Fig. 4(b)). (c) The gaps on the two sides and the bottom surfaces of the connection were sealed with high-strength grouting material at a depth of about $20 \mathrm{~mm}$, while the gap on the top surface remained open (Fig. 4(c)) and (d) Grouting the pockets and sleeves was done 12 hours after sealing the gaps. A grouting machine was used to inject the grouting materials through the grouting inlet hole near the lower edge (Fig. 4(d)) and overflow was allowed from the grout extraction outlet hole near the upper edge. The inlet hole, the extraction hole and the remaining unsealed joint gap were finally sealed with grouting materials after overflow had been observed from all of them.

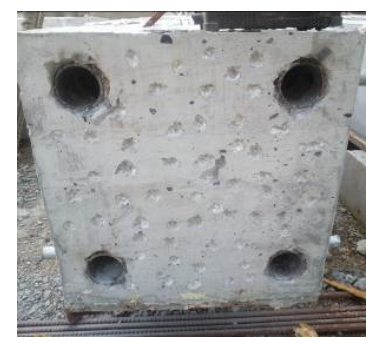

(a) Surface roughening

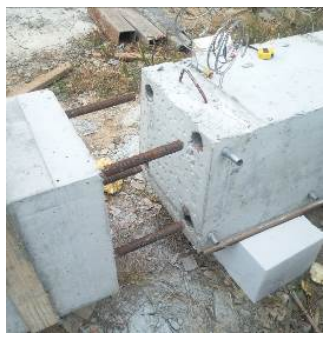

(b) Assembling

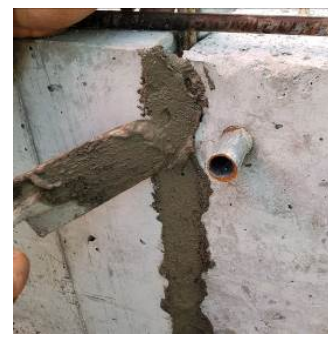

(c) Sealing edge

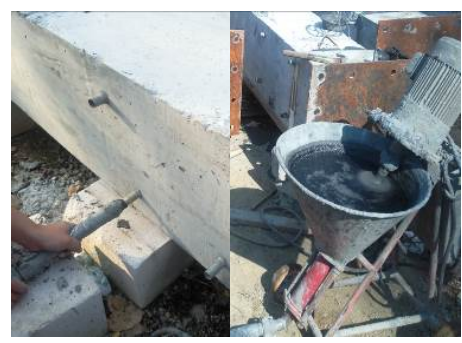

(d) Grouting

Figure 4 Assembly process

All columns were fabricated from one batch of concrete, having a design compressive strength of $40 \mathrm{MPa}$. The mix proportions per cubic meter of concrete, were $360 \mathrm{~kg}$ of cement, $140 \mathrm{~kg}$ of water, $850 \mathrm{~kg}$ of sand, 1045 $\mathrm{kg}$ of stone and $5 \mathrm{~kg}$ of water-reducing agent. In addition, all the precast concrete columns used UJOIN-108 high-strength and non-shrinkage grouting material which met the requirements of Chinese Technical Standard [31]. UJOIN-108 is a dry powder composed of cement as the basic material, with fine aggregate and concrete admixture and other materials. It was manufactured by Wuhan Sanyuan construction materials Ltd, and has good fluidity, early-strength, high-strength and micro-expansion properties after mixing with water. All fire resistance tests were completed within 75-100 days after concrete casting. The average cubic compressive strengths of concrete and grouting material at the time of the fire test ( 75 days) were $46.4 \mathrm{MPa}$ and $96.4 \mathrm{MPa}$, respectively. The steel bars used in the test were hot rolled ribbed steel bars with yield strength of $400 \mathrm{MPa}$ (HRB400). Independent tensile tests showed that the yield strength of the $14 \mathrm{~mm}$ and $28 \mathrm{~mm}$ diameter longitudinal steel bars were $510 \mathrm{MPa}$ and $464 \mathrm{MPa}$, respectively, and their respective ultimate strength were $625 \mathrm{MPa}$ and 605 
MPa. The yield strength of the stirrups was $423 \mathrm{MPa}$, and the ultimate strength was $576 \mathrm{MPa}$.

\subsection{Test apparatus and procedure}

The fire tests were carried out using a multi-functional fire test furnace at Jangsu Key Laboratory of Structural Engineering in China. The fire test furnace is composed of a heating chamber, an automatic fire control system, a fuel supply system, a loading apparatus, a data collection system and a high temperature camera device. The internal height of the furnace is $3.3 \mathrm{~m}$, and the floor area is $3 \mathrm{~m} \times 2 \mathrm{~m}$. The furnace is capable of simulating temperatures up to $1200{ }^{\circ} \mathrm{C}$ by using liquefied petroleum gas (LPG) as fuel and has a maximum loading capacity of $4000 \mathrm{kN}$. More details of the fire test furnaces can be seen in the literature ${ }^{[32]}$. The fire test setup in this paper is shown in Fig. 5 and Fig. 6.

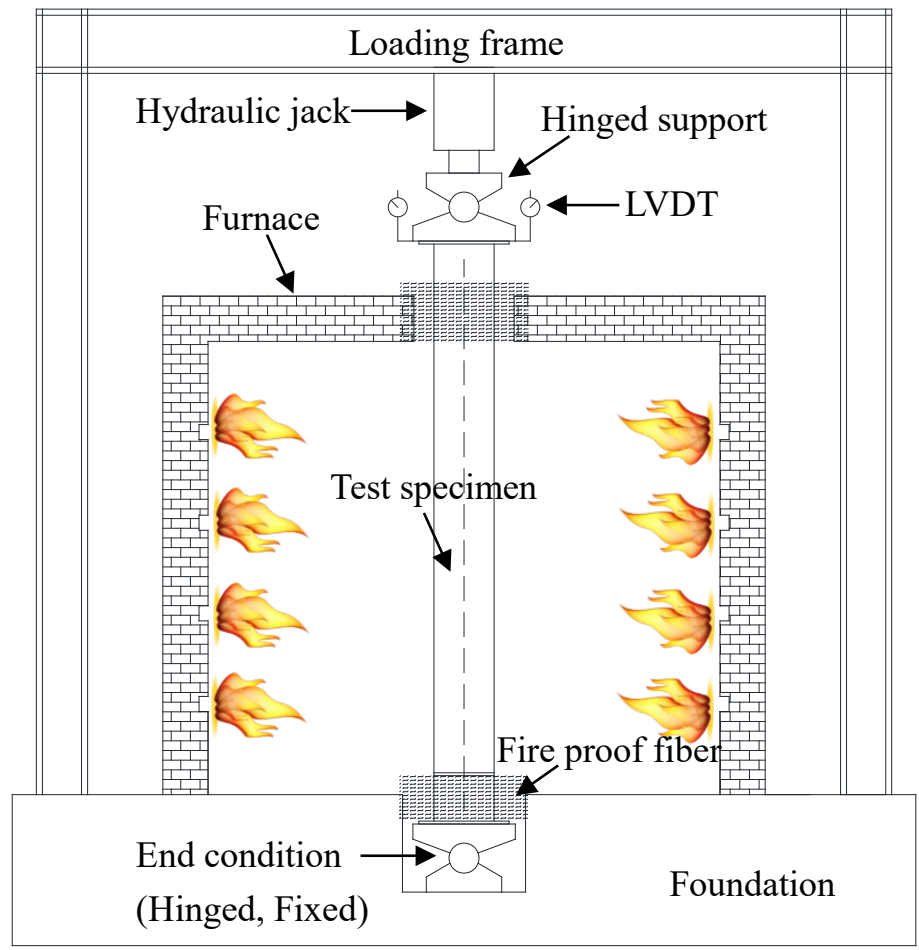

Figure 5 Fire test setup
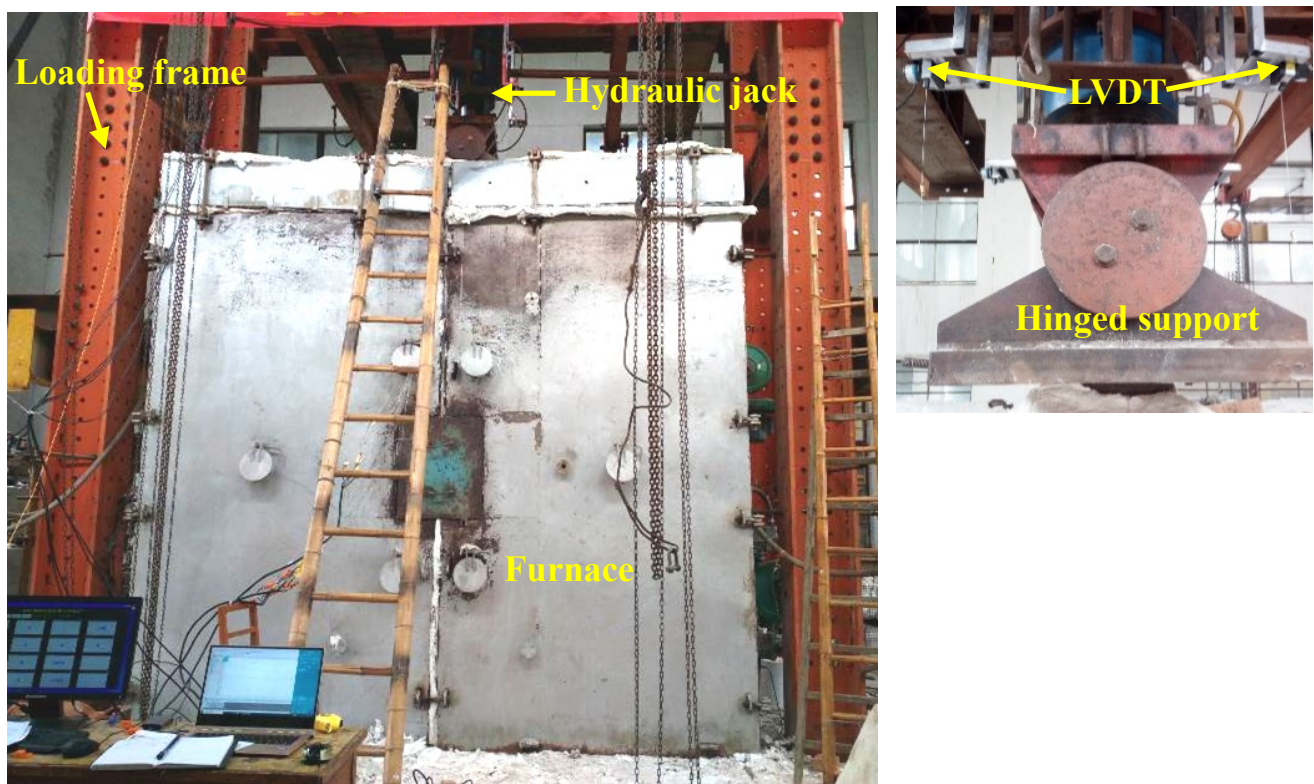

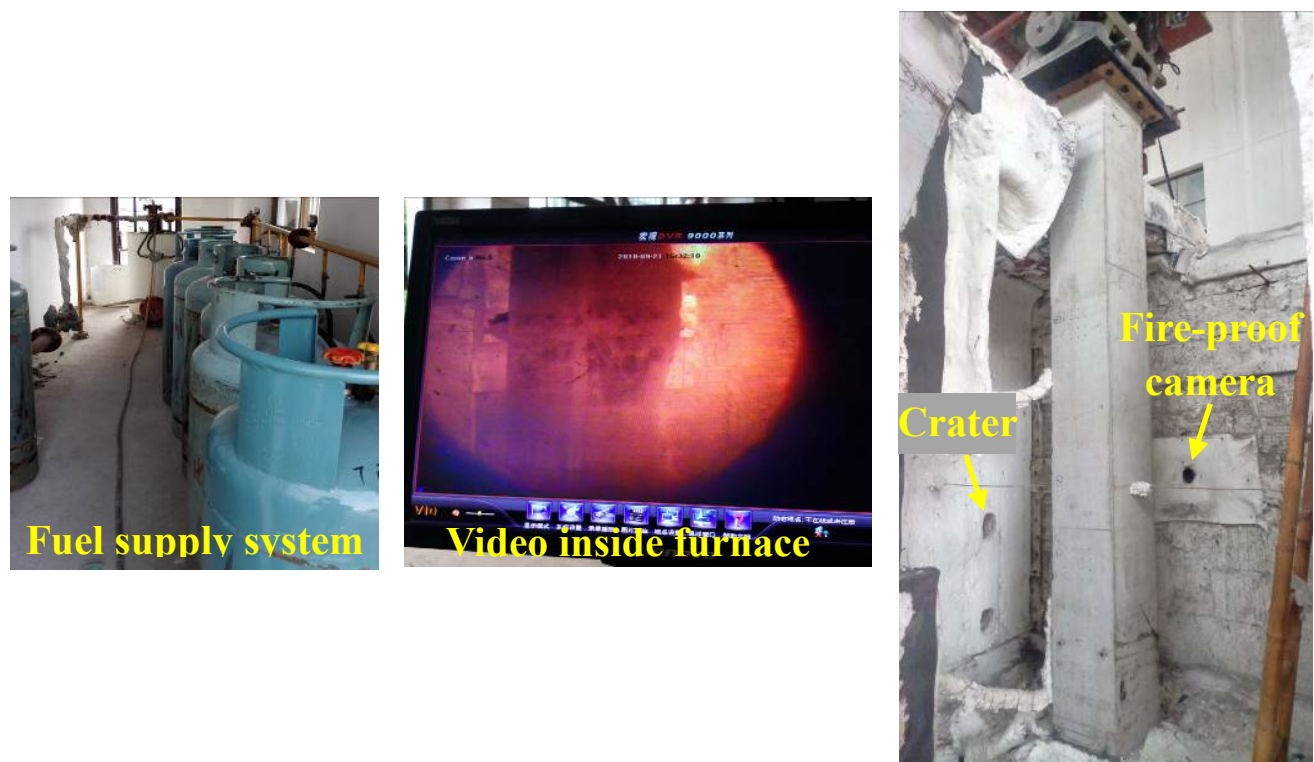

Figure 6 Details of the furnace

The precast column was installed in the furnace by bolting the end plates to the support and the loading head, respectively. For precast columns C-B1, C-B2, D-B1 and D-B2, since global instability was considered, the supporting conditions at the ends were both hinged, and the length of the columns exposed to fire was $3000 \mathrm{~mm}$. For precast columns C-M and D-M, since the tests were to study the failure strength of the connections, both ends of the columns were fixed and the length of the columns exposed to fire was shortened to minimize the occurrence of buckling before failure of the connections. However, due to the limitation of the test conditions, only the lower end was fixed and the upper end remained hinged. All the columns were loaded axially by a hydraulic jack at the top of the loading head.

The test procedure was based on the specifications of GB/T $9978^{[33]}$, which is the Chinese version of ISO 834-1 ${ }^{[34]}$. About an hour before the start of the fire test, the column to be tested was loaded gradually up to the design load that was maintained for 15 minutes. The design load was monitored with a controlled fluctuation of 5\% during the entire test. The fire test followed ISO-834 standard fire curve (Fig. 7(a)). The temperature inside the furnace and the column were measured by the temperature acquisition instrument. The axial displacement of the top end of the column was measured by LVDT. When the hydraulic jack failed to maintain the load, or the columns contracted axially by $0.01 \mathrm{~h} \mathrm{~mm}$ (h is the initial height, in millimeter) or the rate of contraction reached $0.003 \mathrm{~h} \mathrm{~mm} / \mathrm{min}$, it was considered as a sign of failure of the column and the test was terminated. The recorded time from the start of fire to the above mentioned failure was taken as the fire resistance time of the column.

\section{Experimental results and discussions}

\subsection{Failure process and failure mode}

\subsubsection{Precast concrete columns with cluster reinforcement}

During the test, the entire process from initial temperature rise to failure was monitored by the fire-proof camera in the furnace and spalling of concrete was recorded. Except for column C-M, severe spalling occurred in all other columns. Table 2 gives the time and the furnace temperature when spalling started.

Table2 Spalling progression in precast concrete columns

\begin{tabular}{ccccccc}
\hline Precast column & C-B1 & C-B2 & C-M & D-B1 & D-B2 & D-M \\
\hline Spalling time $(\operatorname{mins})$ & 7 & 9 & - & 7 & 8 & 6 \\
Furnace temp. $\left({ }^{\circ} \mathrm{C}\right)$ & 620 & 670 & - & 620 & 650 & 600 \\
\hline
\end{tabular}




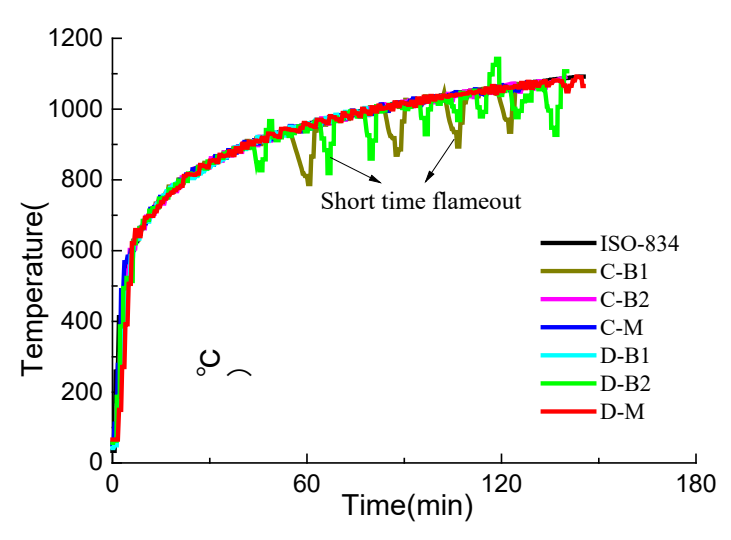

(a) Furnace temperature

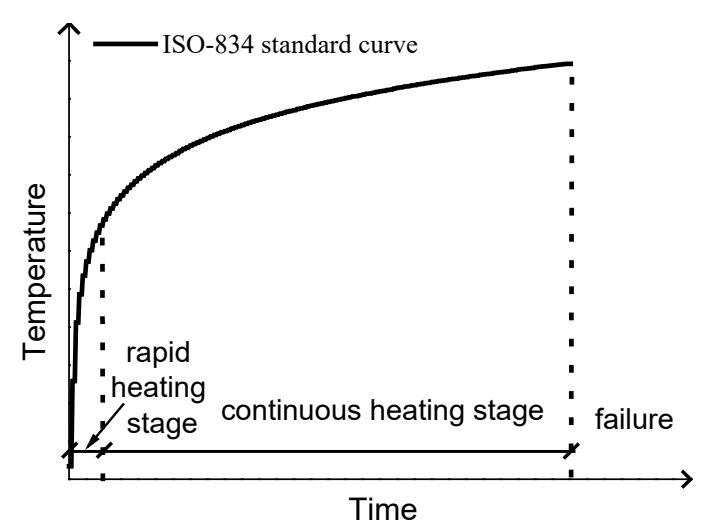

(b) Different heating stages

Figure 7 Furnace temperature and different heating stages

Column C-B1 began to spall explosively at the initial rapid heating stage (Fig. 7(b)). The spalling process lasted about 24 minutes. During the continuous heating stage, the temperature of the concrete and the steel bars continued to rise, and the deformation of the column gradually changes from small axial elongation to axial contraction. After 114 minutes under fire, there were obvious vertical cracks near the middle height of the column (Fig. 8). After 124 minutes under fire, accompanied by a loud noise, concrete crushing occurred on the concave side of the column, resulting in significant local collapse. The longitudinal steel bars were then buckled outward with increased lateral deflection. The applied load could not be maintained any longer, hence, the fire resistance of the column was reached. The failure process of column C-B2 was similar to that of column C-B1. For C-M, the equipment malfunctioned at 133 minutes, so that the test stopped and the column did not fail.
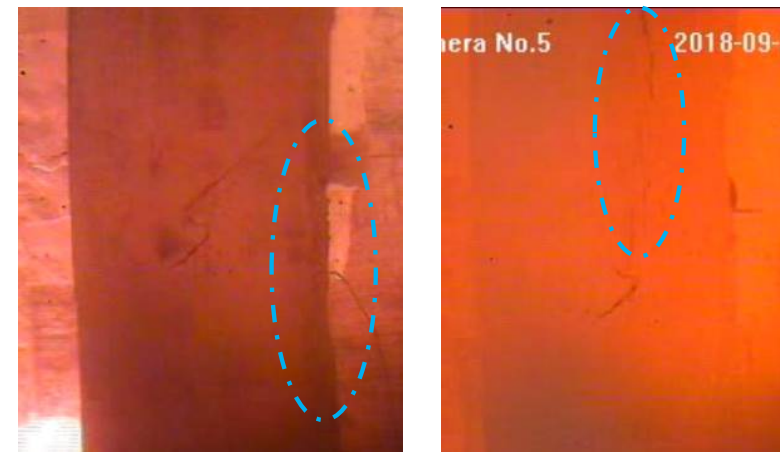

(a) Column C-B1
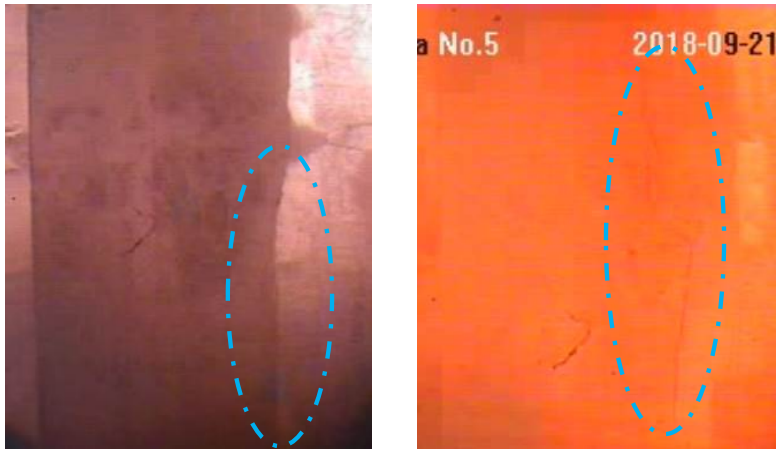

(b) Column C-B2

Figure 8 Spalling and vertical cracking of the precast concrete columns with cluster reinforcement

Figs. 9-10 show the photos of columns C-B1 and C-B2 after testing, respectively. It can be seen that failure occurred in the middle height of the column. Concrete spalling in the failure zone is obviously more extensive than that in the connection zone. The progressive spalling in the connection zone usually reached the stirrups at the most. Other notable phenomena were that some of the locally buckled steel bars appeared very dark in color, which indicated that the steel bars were under fire without fire protection. Thus, it can be argued that the spalling of concrete cover of the steel bars occurred in the early stage of temperature rise, causing rapid temperature rise of the unprotected part. Because of stiffness softening of the longitudinal steel bars, local instability occurred first, which further led to the early collapse of the column.

Only minor surface spalling was found in column C-M (Fig. 11(a)), which was not expected for this batch of specimens. The column was placed in the unignited furnace overnight after several minutes of repeated heating (furnace temperature $<600{ }^{\circ} \mathrm{C}$ ). Because the preheating effect, the moisture content of the column was reduced and the probability of explosive spalling was significantly reduced in the next day's test. In addition, it was found that horizontal cracks occurred along the grouting seam of column C-M (Fig. 11(c)). Other columns 
had similar crack patterns.

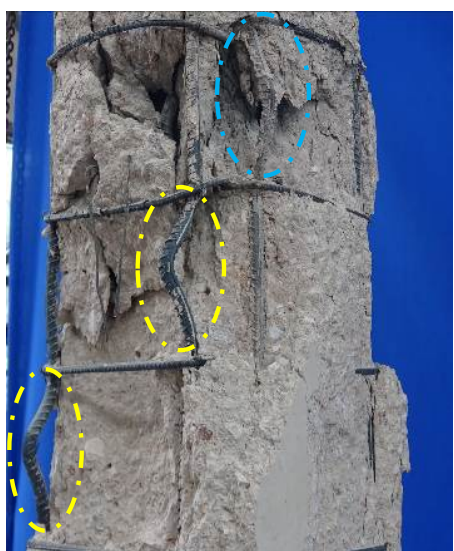

(a) Local buckling

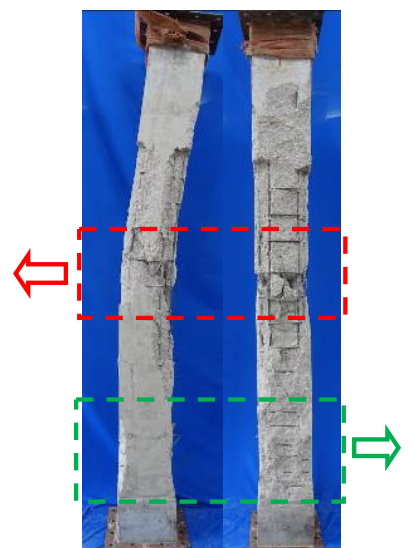

(b) General view

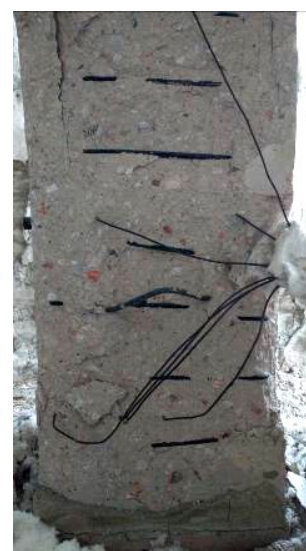

(c) Surface spalling

Figure 9 Column C-B1 after testing

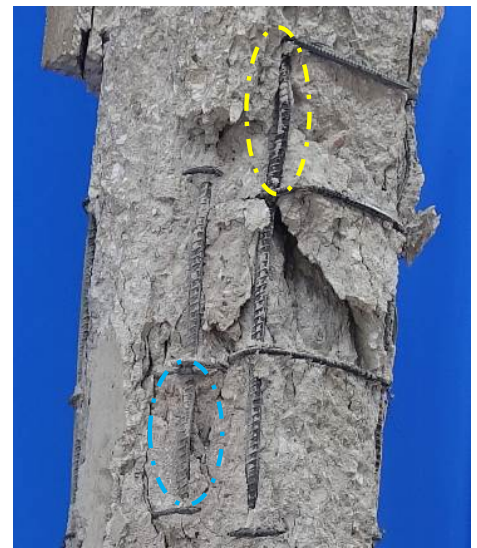

(a) Local buckling

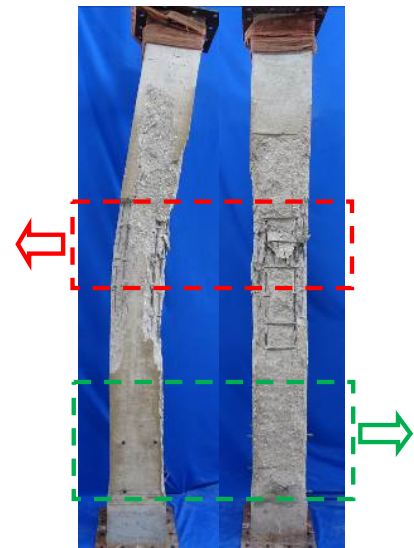

(b) General view

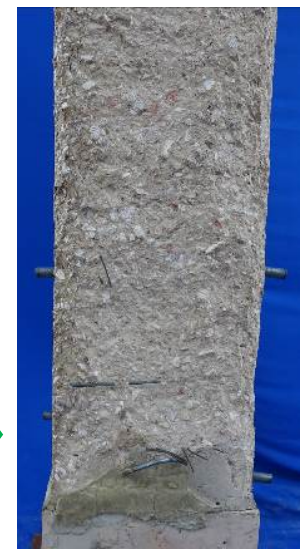

(c) Surface spalling

Figure 10 Column C-B2 after testing

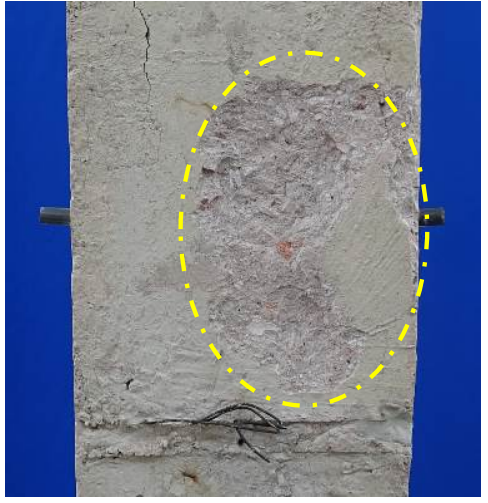

(a) Slight spalling

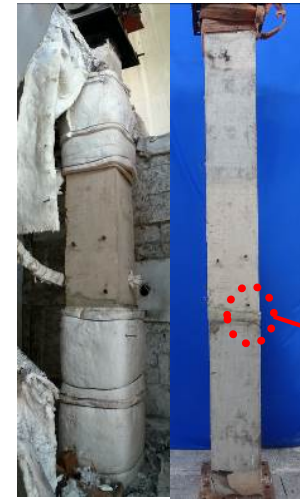

(b) General view

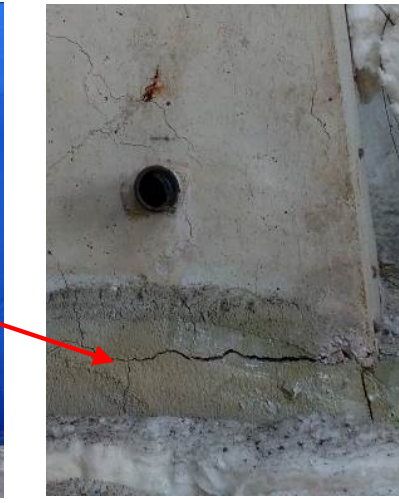

(c) Cracking at the seam

Figure 11 Column C-M after testing

\subsubsection{Precast concrete columns with large-diameter reinforcement}

Figs. 12-14 show column D-B1, D-B2 and D-M, respectively, after testing. It can be seen that failure of columns D-B1 and D-B2 occurred at 2/3 and half of the column height, respectively. Some stirrups were disintegrated and fell off. Part of the buckled longitudinal bars spanned 2-3 times the stirrup spacing, and the concrete cover almost completely spalled. In addition, one of the four longitudinal bars was darker in color with surface damage and shorter buckling length, which was obviously different from the other three (Fig. 12). This was attributed to a long-time exposure to fire due to the explosive spalling of the concrete cover which appeared 
to have accelerated the failure of the column.

The failure of column D-M occurred above the connection zone though the thickness of the concrete cover of the grouted sleeves was thinner. The spalling in the non-connection zone was more severe, where some stirrups were pulled off due to the long fire exposure time.

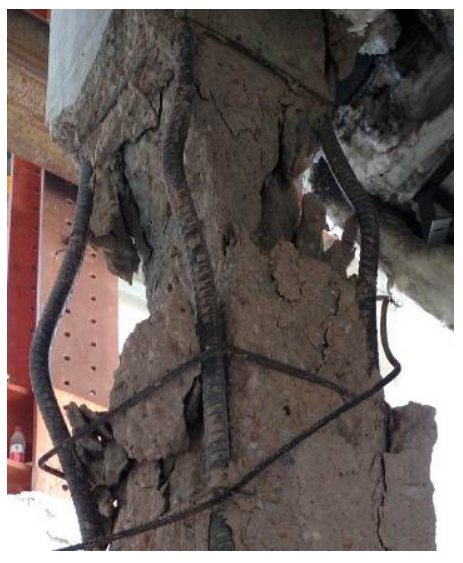

(a) Crush and buckling

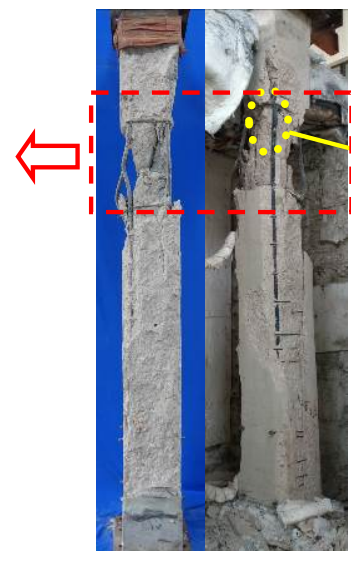

(b) General view

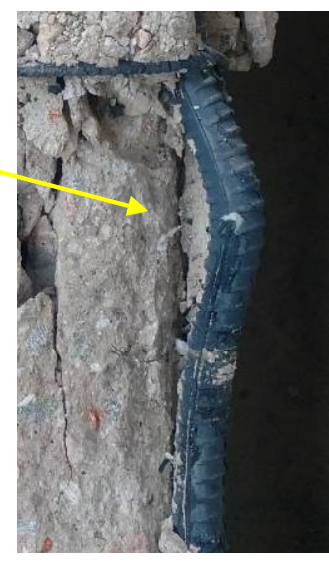

(c) Long time exposure

Figure 12 Column D-B1 after testing

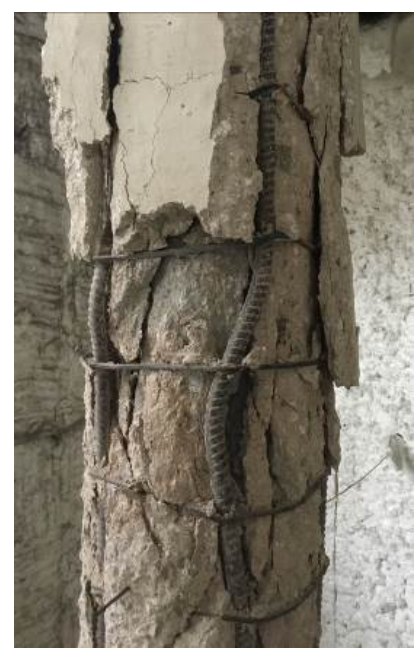

(a) Spalling and buckling

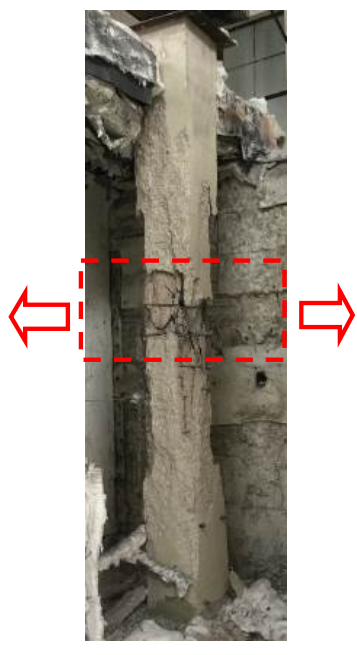

(b) General view

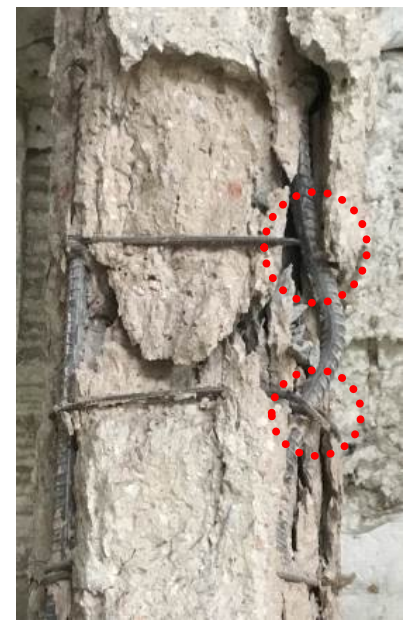

(c) Stirrups failure

Figure 13 Column D-B2 after testing

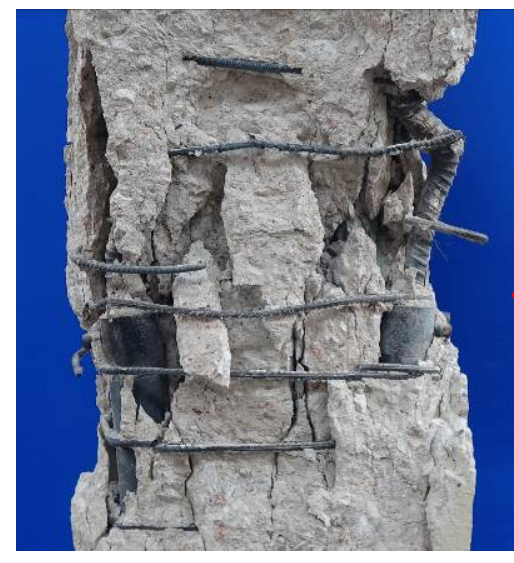

(a) Local buckling and stirrups failure

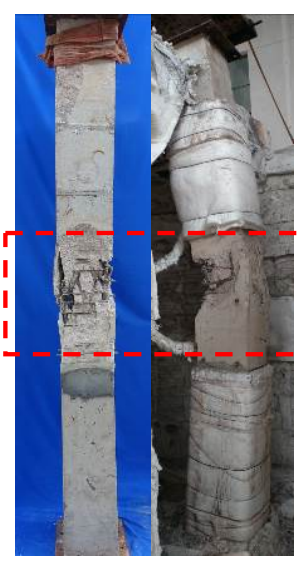

(b) General view

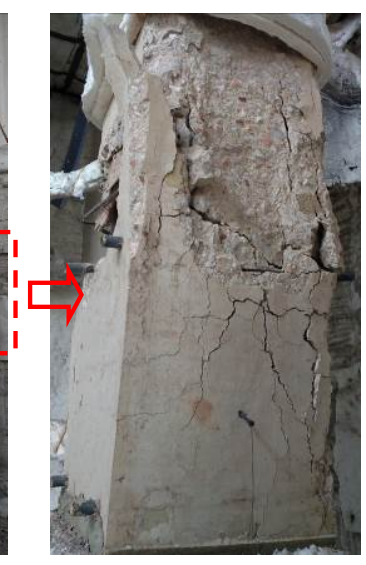

(c) Surface spalling

Figure 14 Column D-M after testing

\subsubsection{Comparisons of the two precast concrete columns reinforced by efficient reinforcement}

By comparing the failure modes of the precast concrete columns with cluster reinforcement and those with 
large-diameter reinforcement when they had extended length exposed to fire, it can be seen that the two types of precast columns failed at similar locations. The failure occurred in a region where the stirrups were less dense and was outside of the connection zone of the column, while only surface explosive spalling of the concrete cover was found in the column where the stirrups were dense (including the connection zone). This demonstrated that the use of densified stirrups had enhanced the confinement of the concrete core and the longitudinal reinforcement, so that spalling was reduced and the fire resistance of the densified part was improved. Concerning the damage on the section at the location of failure, the precast concrete columns with large-diameter rebar reinforcement had more serious damage than those with cluster reinforcement. There are two possible reasons for this. On the one hand, the depth of spalling induced by the fire on the damaged sections was virtually the same as the thickness of the concrete cover. Thus, the precast concrete columns with large-diameter reinforcement, which had thicker concrete cover, experienced greater damage on the cross-sections of the columns. On the other hand, compared with the new configuration of confining reinforcement in the precast concrete columns with cluster reinforcement, the traditional arrangement of stirrups had smaller confining effect on the columns with large-diameter rebar reinforcement. As a result, when failure occurred, the stirrups were disintegrated, the buckling length of the longitudinal reinforcement was longer and the concrete core was crushed.

\subsection{Thermal response}

Fig. 15 shows the average furnace temperature and the temperatures at various depths into the concrete and of the steel rebar for different columns in the fire tests. It can be seen that the measured furnace temperature follows closely with the specified ISO-834 standard temperature-time curve over most of the time. Some fluctuations in the furnace temperature, when column C-B1 and D-B2 were tested, were mainly caused by several short-term flameouts due to equipment malfunction. The temperature measurement of column D-M in the first 35 minutes was not available due to an unexpected malfunction of the temperature collector.

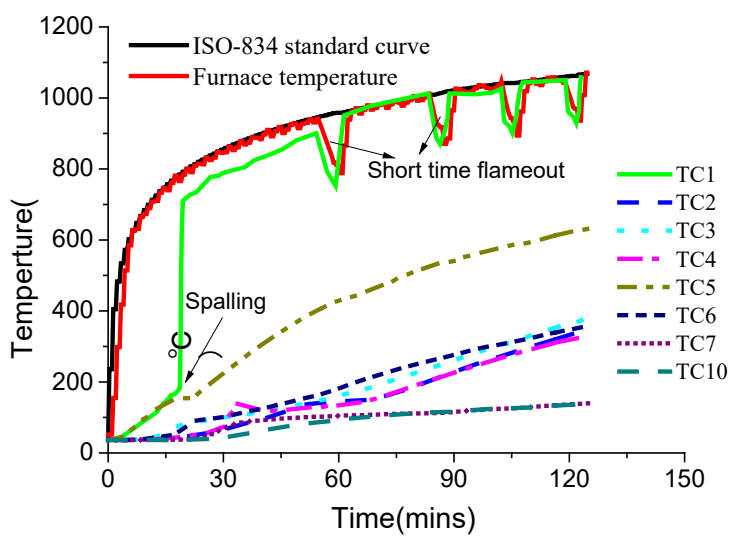

(a) Column C-B1

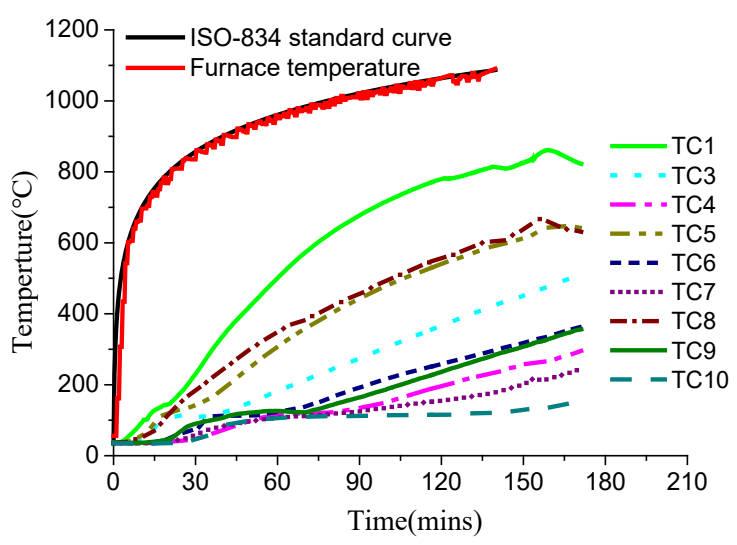

(c) Column C-B2

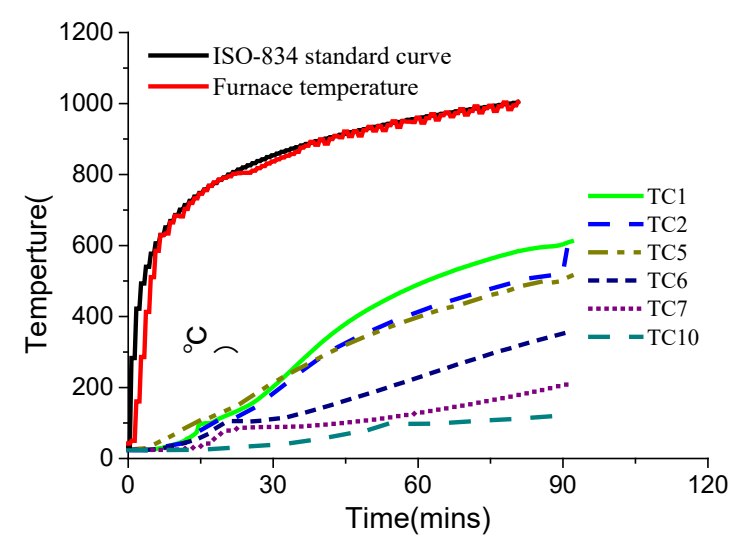

(b) Column D-B1

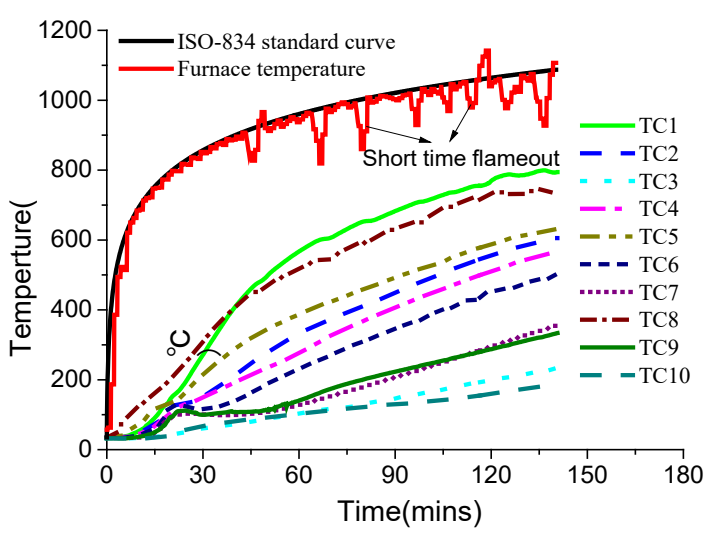

(d) Column D-B2 


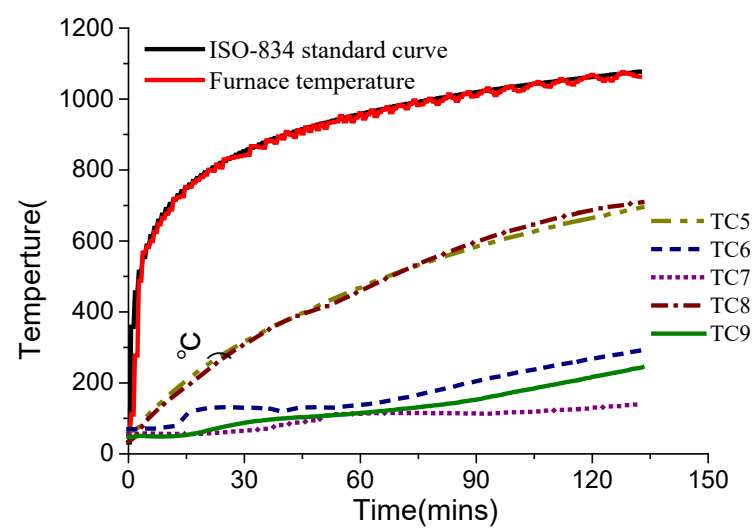

(e) Column C-M

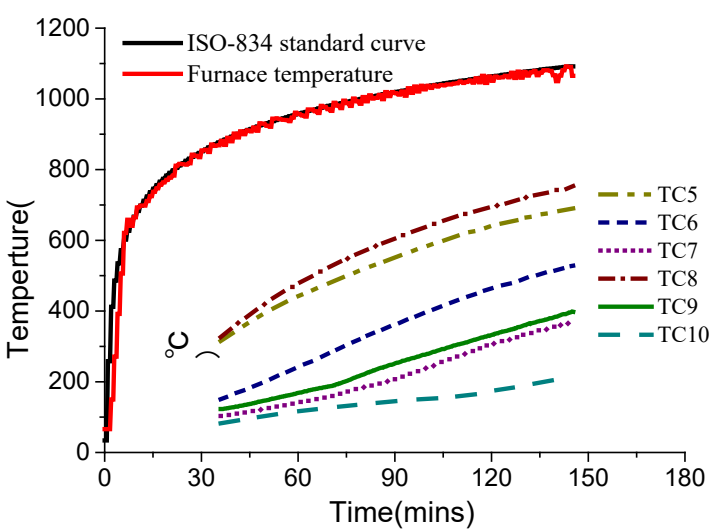

(f) Column D-M

Figure 15 Measured temperatures as a function of time at furnace and various depths in precast columns

The temperature curves recorded by each of the thermal couples (TC) in Fig. 15 show that the measured temperature decreases significantly with the increase of depth from the surface, which was due to the low concrete thermal conductivity that caused a slow rate of heat transfer ${ }^{[32]}$. For all the tested columns, the rate of temperature rise in concrete was slowed down at around $100{ }^{\circ} \mathrm{C}$. This phenomenon has been reported by many authors ${ }^{[8,18]}$ and can be mainly attributed to the evaporation of free water in concrete, which consumes a large amount of heat. In addition, the temperature of the steel bars in some of the columns appears to rise faster at certain times, e.g., TC1 at 18 minutes for column C-B1 and at 15 minutes for column D-B2. This phenomenon was mainly caused by the fire-induced concrete spalling, which reduced the thickness of the protective concrete layer of the steel bars and accelerated the temperature rise.

After 90 minutes under fire, the average temperature of the longitudinal steel bars of the columns with large-diameter reinforcement was about $560{ }^{\circ} \mathrm{C}$. In this case, the distances from the centers of the 4 large diameter steel bars to their respective nearest fire-exposed surfaces were the same and equal to $64 \mathrm{~mm}$. For the columns with cluster rebar reinforcement, the minimum and maximum distances from the individual steel bars to their nearest fire-exposed surfaces were $37 \mathrm{~mm}$ and $90 \mathrm{~mm}$, respectively. The measured average temperatures at these locations were, respectively, $560^{\circ} \mathrm{C}$ and $230^{\circ} \mathrm{C}$. When the columns failed, the respective temperatures at the above mentioned locations were about $650{ }^{\circ} \mathrm{C}$ for the columns with large diameter rebar reinforcement, and $700{ }^{\circ} \mathrm{C}$ and $340{ }^{\circ} \mathrm{C}$ for the columns with cluster rebar reinforcement. It can be seen that the average temperature of all the longitudinal steel bars of the columns with cluster reinforcement is significantly lower than that of the columns with large diameter reinforcement. The temperature of some of the steel rebar in the cluster reinforcement remained below $400{ }^{\circ} \mathrm{C}$ up to the point of failure, which had enhanced the fire resistance of the columns because these steel rebars nearly retained its full strength at a temperature below $400{ }^{\circ} \mathrm{C}$.

As can be seen from Fig. 15(b) (d) and (f), the curves in dark yellow (TC5) and navy blue (TC6) show that during the heating process, the maximum difference of the sleeves' surface temperature was about $150 \sim 200{ }^{\circ} \mathrm{C}$ and the respective heating time was about $45 \sim 65 \mathrm{~min}$, though the steel had a very high thermal conductivity. This suggests that the temperature distribution on the cross sections of the grouted sleeves is not uniform as a results of the temperature difference on the sleeve surfaces, which is mainly because the much lower temperature of the concrete around the part of the sleeve surfaces that are away from the fire-exposed surfaces of the columns and dissipate some of the heat from the sleeves.

\subsection{Structural response and fire resistance}

The measured axial deformation of the precast concrete columns with time is shown in Fig. 16. It can be seen that the axial deformation of the columns under fire exposure can be divided into three stages: (1) small expansion, (2) gradual contraction and (3) abrupt shortening. In the early stage of heating, the thermal strain causes expansion of the column. All the tested columns underwent small axial expansion with a maximum of 1 $\mathrm{mm}$ registered in column C-M. As the temperature rises, the strength and elastic modulus of the concrete, 
grouting material and steel decreased, which leads to increased instantaneous stress-dependent strains. The creep and transient state strains becomes more and more significant at higher temperature, and gradual contraction of the column starts. By comparing the axial deformations of columns C-B1 and D-B1, and columns C-B2 and D$\mathrm{B} 2$, it can be seen that the contraction of the columns with cluster reinforcement is larger than that with largediameter reinforcement. The maximum contraction of $8.6 \mathrm{~mm}$ was measured in column C-B2. When the bearing capacity of the column was lower than the applied load, the column failed, accompanied with significant deformation.

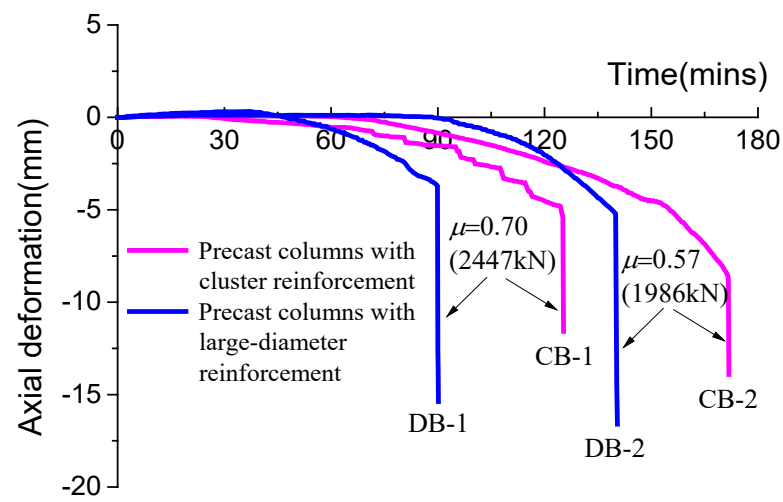

(a) Extended length exposed to fire

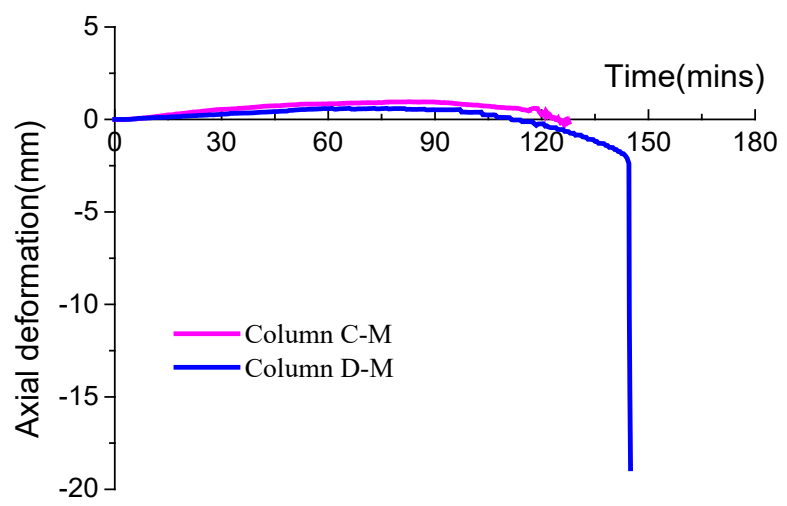

(b) Local exposed to fire

Figure 16 Measured axial deformations of the precast column as a function of time

The fire resistance of precast concrete columns C-B1, C-B2, D-B1, D-B2 and D-M from the tests are 124 min, $172 \mathrm{~min}, 91 \mathrm{~min}, 140 \mathrm{~min}$ and $145 \mathrm{~min}$, respectively, while that of column C-M exceeds $133 \mathrm{~min}$. It can be seen that the load ratio, form of efficient reinforcement and fire conditions are important factors that affect fire resistance of the precast concrete columns. As expected, the higher the load level is, the lower the fire resistance will be. From the comparisons between C-M and C-B1, column D-M and D-B1, which have similar characteristics except that they were subjected to different fire conditions, it can be seen that the fire resistance of the precast concrete columns with local fire exposure is obviously higher than those exposed to fire over an extended length. This further illustrates that the fire resistance of the connection zone of the precast columns is higher than that of the non-connection zone. From the comparisons of columns C-B1 with D-B1 and columns C-B2 with D-B2, of which the form of efficient reinforcement is the only variables, it can be seen that the fire resistance of the precast concrete columns reinforced by cluster reinforcement is $23 \%$ and $36 \%$ higher than that of those reinforced by large-diameter reinforcement at a design load ratios of 0.57 and 0.70 , respectively. This enhanced fire resistance is mainly due to that (a) the bundle-shaped longitudinal rebar of the cluster reinforcement occupied a wider area than the single large-diameter rebar on the cross section of the column. The steel bars farther into the concrete section have lower temperature and less reduction in strength due to better fire protection, which contributes positively to the bearing capacity of the column; and (b) the damage on the cross-sections of the columns with large-diameter reinforcement, as mentioned above, is more severe than that of the columns with cluster reinforcement due to the fire-induced spalling and the configuration of stirrups, which reduces the bearing capacity of the column.

\section{Applicability analysis of the simplified approach for calculating fire resistance of precast concrete columns reinforced by efficient reinforcement}

\subsection{Comparison and analysis of existing methods without considering concrete spalling}

The fire resistance of the above tested precast concrete columns with efficient reinforcement was evaluated using the formulas presented in Eurocode $2^{[26]}$, DBJ/T 15-81 ${ }^{[27]}$ and Kodur ${ }^{[29]}$.

Eurocode $2^{[26]}$ provides analytical formula for calculating fire resistance of reinforced concrete columns subjected to a standard fire exposure, in which number and location of longitudinal steel bars, load ratio, column 
cross-sectional size, thickness of concrete cover and effective length were taken into account, as follows:

$$
R=120\left(\left(R_{\eta f i}+R_{a}+R_{l}+R_{b}+R_{n}\right) / 120\right)^{1.8}
$$

where

$$
\begin{gathered}
R_{\eta f i}=83\left[1-\mu_{\mathrm{fi}} \frac{(1+\omega)}{\left(0.85 / \alpha_{c c}\right)+\omega}\right] \\
R_{a}=1.60(a-30), R_{l}=9.60\left(5-l_{o, f i}\right) \\
R_{n}= \begin{cases}0 & \text { for } n=4(\text { corner bars only }) \\
12 & \text { for } n>4\end{cases}
\end{gathered}
$$

in which, $R$ is fire resistance; $\mu_{\mathrm{fi}}$ is a reduction factor for the design load level in a fire situation, $\omega$ denotes mechanical reinforcement ratio at normal temperature conditions, $\alpha_{c c}$ is the coefficient for compressive strength; $a$ is the axis distance to the longitudinal steel bars (mm), $25 \mathrm{~mm} \leq a \leq 80 \mathrm{~mm} ; l_{o, f i}$ is the effective length of a column under fire conditions, $2 m \leq l_{o, f i} \leq 6 m ; R_{b}=0.09 b^{\prime}, b^{\prime}=A_{\mathrm{c}} /(b+h)$ for rectangular cross-sections or the diameter of circular cross-sections, $200 \mathrm{~mm} \leq b^{\prime} \leq 450 \mathrm{~mm}, h \leq 1.5 b ; n$ is the number of longitudinal steel bars.

DBJ/T 15-81 ${ }^{[27]}$ provides a simplified formula for calculating fire resistance of reinforced concrete columns with rectangular cross-section based on numerical simulations and parametric regression. The formula also takes into account the influence of load ratio, effective length, cross-sectional size and reinforcement ratio. In addition, the formula is applicable to columns subjected to a bi-eccentric axial force, as following:

$$
R_{T}=\beta_{\mu} \beta_{L} \beta_{h d b} \beta_{b} \beta_{e} \beta_{\rho}
$$

where

$$
\begin{gathered}
\beta_{\mu}=c_{1} \mu^{2}+c_{2} \mu+c_{3} \\
\beta_{L}=c_{4} L+c_{5}, \beta_{b}=c_{9} b+c_{10} \\
\beta_{h d b}=c_{6}\left(\frac{h}{b}\right)^{2}+c_{7}\left(\frac{h}{b}\right)+c_{8} \\
\beta_{e}=c_{11} e^{3}+c_{12} e^{2}+c_{13} e+c_{14} \\
\beta_{\rho}=c_{15} \rho+c_{16}
\end{gathered}
$$

in which, $R_{T}$ denotes fire resistance; $\mu$ is the load ratio, $0.2 \leq \mu \leq 0.7 ; L$ is the effective length of the column, $2 m \leq L \leq 4 m ; h$ and $b$ are the height and width of the column section, respectively, $0.3 m \leq b \leq 0.6 m, b \leq h \leq 0.6 m$; $e$ is eccentricity, $0.0 \leq e \leq 2.0 ; \rho$ is the longitudinal reinforcement ratio, $1 \% \leq \rho \leq 3 \%$; The value of coefficient $c_{1} \sim c_{16}$ are shown in $\mathrm{DBJ} / \mathrm{T}^{[27]}$.

Based on the numerical simulations and parametric studies, Kodur ${ }^{[29]}$ proposed the following simplified formula for evaluating fire resistance of reinforced concrete columns under biaxial bending, in which the effects of fire-induced spalling, 1-, 2-, 3-, or 4-sided fire exposure, bi-eccentric loading and design fire scenarios were taken into account, as following:

$$
R=C_{t}\left[8 \times k_{s h} \times k_{c p} \times\left(30-\left(S_{R}+5\right) \times\left(\mathrm{L}_{R}-0.2\right)\right)\right]^{0.94}
$$

in which, $R$ is the fire resistance; $k_{s h}=k_{e c} \times k_{s p}, k_{e c}$ is a constant based on the load eccentricity, load ratio and slenderness ratio; $k_{s p}$ is a constant associated with spalling, $k_{s p}=1$, when perm $\geq 10^{-17} \mathrm{~m}^{2}$, where perm is the intrinsic permeability of concrete $\left(\mathrm{m}^{2}\right) ; k_{s p}=[\log ($ perm $)+20] / 2.75$, for rectangular columns when perm $\leq 10^{-17} \mathrm{~m}^{2}$ (with no polypropylene fibers); $C_{t}, k_{c p}, S_{R}$ and $\mathrm{L}_{R}$ are calculated from literature ${ }^{[29]}$.

Typical examples are used here to compare the above simplified calculation methods. Fig. 17 shows the 
fire resistance of reinforced square concrete columns against some of the influential factors. The initial design of the columns are as follows. The side length of the square columns is $400 \mathrm{~mm}$; the reinforcement ratio is 0.0154 ; the concrete cover thickness is $48 \mathrm{~mm}$; the load ratio is 0.4 ; the effective length is $3 \mathrm{~m}$ and the columns are centrally loaded. The intrinsic permeability of the concrete is more than $10^{-17} \mathrm{~m}^{2}$. In the following parametric study, all the above parameters are fixed to the designed values except one of them, each time, is allowed to vary.

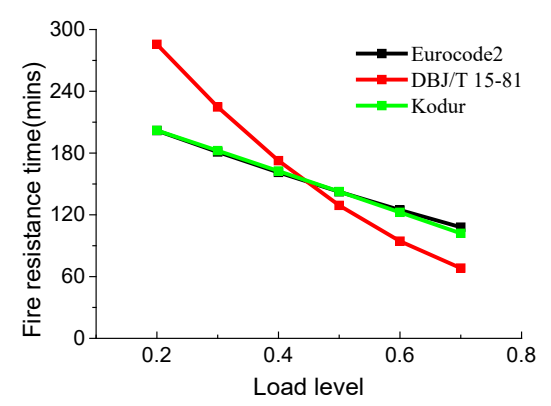

(a) Load ratio

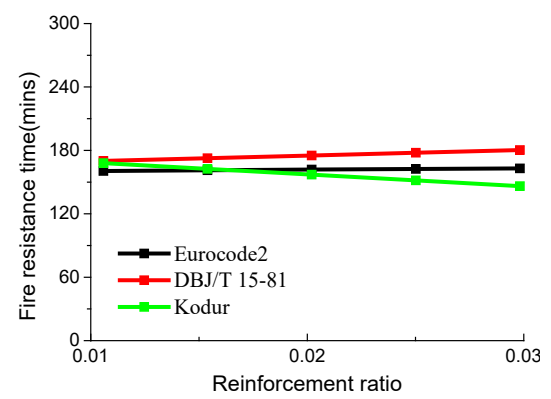

(d) Reinforcement ratio

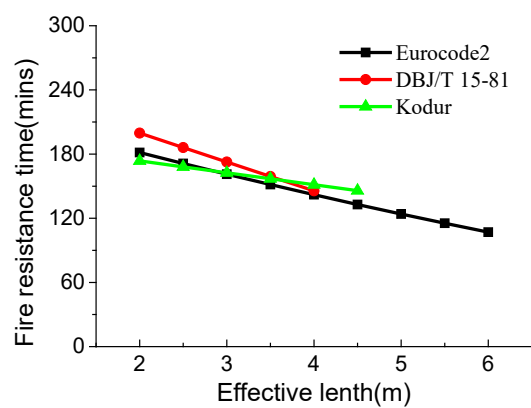

(b) Effective length

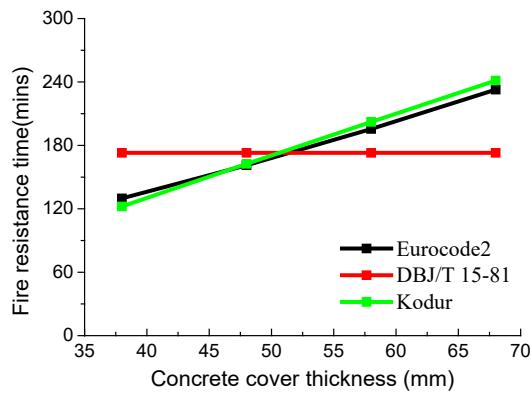

(e) Concrete cover thickness

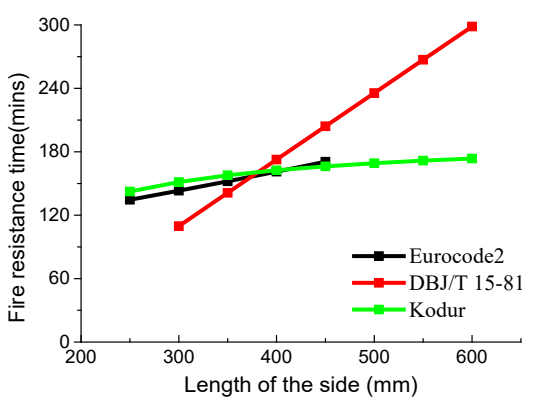

(c) Cross-sectional size

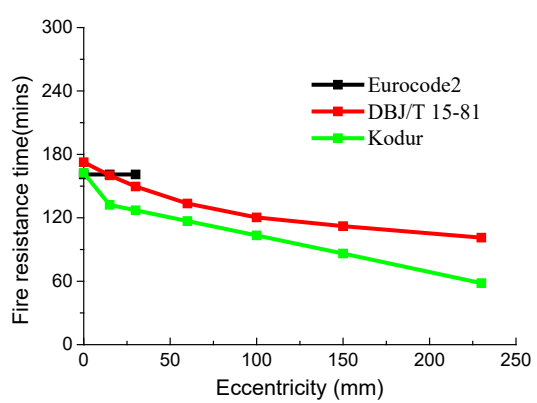

(f) Eccentricity

Figure 17 Comparison of simplified calculation methods for fire resistance of reinforced concrete columns

It can be seen from Fig. 17 that the fire resistances calculated from the three simplified calculation methods for varying effective lengths, varying reinforcement ratios and small eccentricity are close to each other. For different load ratios, cross-sectional size and concrete cover thickness, the calculated results of Eurocode 2 and Kodur's approach are very close, but less so when compared with those of DBJ/T 15-81. Except that the thickness of concrete cover is not considered in DBJ/T 15-81, the calculated fire resistance of DBJ/T 15-81 is more sensitive to the load ratio and cross-sectional size than the Eurocode 2 and Kodur's approaches.

Table 3 shows the comparison of the fire resistance calculated by the above three methods with the test results. It is worthwhile to mention that when using Kodur's formula, two different intrinsic permeability of concrete, i.e., perm $=10^{-18} \mathrm{~m}^{2}$ and perm $=10^{-19} \mathrm{~m}^{2[29]}$ were considered because the values of them were not clearly given, and the concrete spalling phenomena occurred in the test were taken into account. The two sets of results

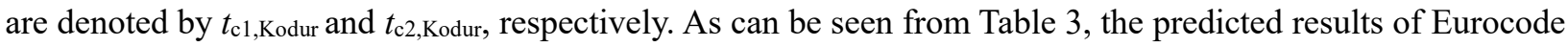
2 and DBJ/T 15-81 are generally not conservative, mainly because they do not consider the impact of severe spalling of the tested columns. Kodur's approach takes into account the impact of fire-induced spalling, but the results are affected by concrete permeability, as shown by the two sets of results relative to the two different permeability.

In addition, the DBJ/T 15-81 and Kodur's formulas are almost identical in predicting fire resistance of the two types of precast concrete columns, because they do not consider the form of reinforcements. In contrast, Eurocode 2 takes into account the adverse effect of placing only four longitudinal steel bars at the corners on the fire resistance of the concrete columns, so that the predicted fire resistance of the columns with large-diameter reinforcement are smaller than that of the columns with cluster reinforcement. However, the impact of cluster reinforcement on the fire resistance of concrete columns was not properly considered yet in practical design. The comparisons in Table 3 show that the three existing simplified calculation methods have some limitations in 
predicting fire resistance of precast concrete columns reinforced by efficient reinforcement.

Table 3 Comparison of measured and predicted fire resistance of the precast concrete columns

\begin{tabular}{|c|c|c|c|c|c|c|c|c|c|}
\hline \multirow{3}{*}{$\begin{array}{c}\text { Precast } \\
\text { Columns }\end{array}$} & \multicolumn{5}{|c|}{ Fire resistance (min) } & \multirow{2}{*}{\multicolumn{4}{|c|}{ Ratios }} \\
\hline & \multirow{2}{*}{$\begin{array}{c}\text { Test, } \\
t_{\mathrm{t}}\end{array}$} & \multicolumn{4}{|c|}{ Calculated } & & & & \\
\hline & & $\begin{array}{c}\text { Eurocode2, } \\
t_{\mathrm{c}, \mathrm{EC} 2}\end{array}$ & $\begin{array}{l}\mathrm{DBJ} / \mathrm{T} 15 \\
-81, t_{\mathrm{c}, \mathrm{DBJ}}\end{array}$ & $\begin{array}{l}\text { Kodur, } \\
t_{\mathrm{c} 1, \text { Kodur }}\end{array}$ & $\begin{array}{l}\text { Kodur, } \\
t_{\mathrm{c} 2 \text {,Kodur }}\end{array}$ & $\begin{array}{c}t_{\mathrm{c}, \mathrm{EC} 2} \\
/ t_{\mathrm{t}}\end{array}$ & $\begin{array}{c}t_{\mathrm{c}, \mathrm{DBJ}} \\
/ t_{\mathrm{t}}\end{array}$ & $\begin{array}{c}t_{\mathrm{c} 1, \text { Kodur }} \\
/ t_{\mathrm{t}}\end{array}$ & $\begin{array}{c}t_{\mathrm{c} 2, \text { Kodur }} \\
/ t_{\mathrm{t}}\end{array}$ \\
\hline C-B1 & 124 & 199 & 150 & 158 & 82 & 1.60 & 1.21 & 1.27 & 0.66 \\
\hline $\mathrm{C}-\mathrm{B} 2$ & 172 & 216 & 186 & 178 & 93 & 1.26 & 1.08 & 1.03 & 0.54 \\
\hline C-M & $>133$ & 241 & 200 & 179 & 93 & - & - & - & - \\
\hline D-B1 & 91 & 171 & 146 & 155 & 81 & 1.88 & 1.60 & 1.70 & 0.89 \\
\hline D-B2 & 140 & 187 & 181 & 175 & 91 & 1.34 & 1.29 & 1.25 & 0.65 \\
\hline \multirow[t]{3}{*}{ D-M } & 145 & 210 & 194 & 177 & 92 & 1.45 & 1.34 & 1.22 & 0.64 \\
\hline & & & & \multicolumn{2}{|c|}{ Average } & 1.50 & 1.31 & 1.30 & 0.68 \\
\hline & & & & \multicolumn{2}{|c|}{ Standard deviation } & 0.22 & 0.17 & 0.22 & 0.12 \\
\hline
\end{tabular}

\subsection{A new simplified approach for calculating fire resistance considering concrete spalling}

In order to consider the influence of concrete spalling more accurately on the fire behavior of the columns, and to consider the contribution of different longitudinal reinforcement methods to the bearing capacity of the columns under elevated temperatures, a simplified method based on Eurocode 2 and considering concrete spalling in calculating load bearing capacity of reinforced concrete columns subjected to fire is proposed. The applicability of the new approach to precast concrete columns reinforced by efficient reinforcement is also discussed.

Eurocode $2^{[26]}$ provides the "Zone method" for the design of structural members subjected to a standard fire exposure, which is particularly suitable for column design. For a cross-section of a reinforced concrete column exposed to fire, the calculation process using the "Zone method" is summarized below for a square section subjected all round fire:

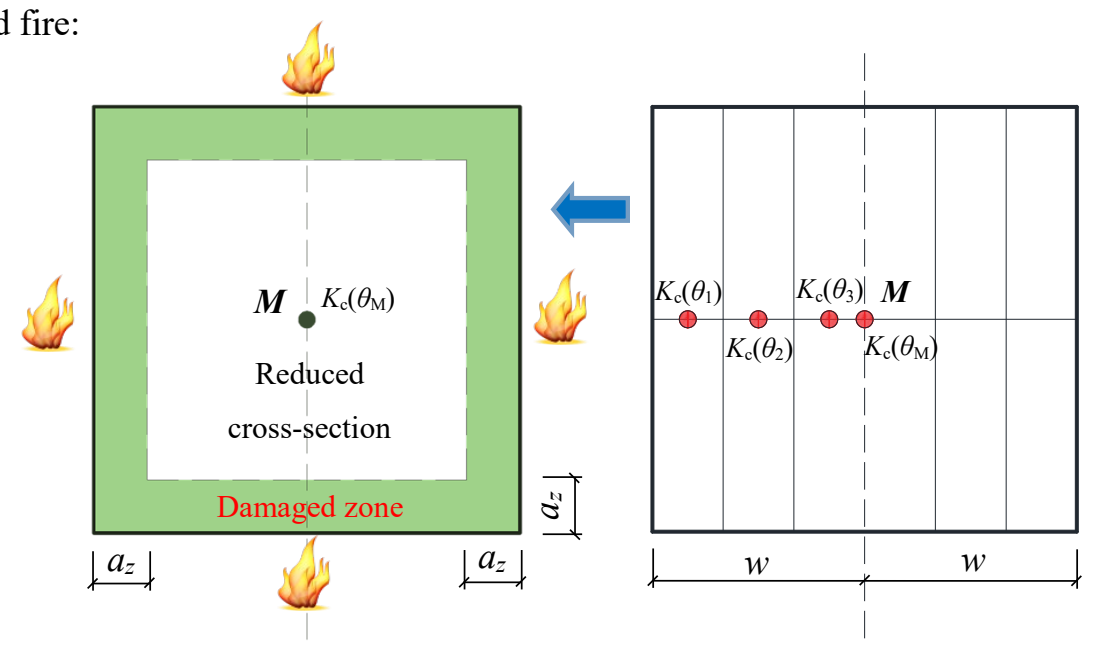

Figure 18 Division and reduction of a column cross-section exposed to fire

a). The cross-section damaged by fire is represented by a reduced cross-section ignoring the damaged zone of thickness $a_{\mathrm{z}}$ at all the sides exposed to fire (see Fig. 18). Point $M$ is the geometric center of the cross-section. It is used to determine the reduced compressive strength of the reduced cross section.

b). Each side of $M$ is divided into $n$ parallel zones of equal thickness, where $n \geq 3$ (see Fig. 18). The temperature at the centers of each zones is calculated and the reduction factor of compressive strength of the zones, $k_{\mathrm{c}}\left(\theta_{\mathrm{i}}\right)$ are determined. The mean reduction coefficient $k_{\mathrm{c}, \mathrm{m}}$ of the cross-section is calculated by 


$$
k_{c, m}=\frac{(1-0.2 / n)}{n} \sum_{i=1}^{n} k_{c}\left(\theta_{i}\right)
$$

Subsequently, the width of the damaged zone $a_{z}$ of the column is calculated as

$$
a_{z}=w\left[1-\left(\frac{k_{c, m}}{k_{c}\left(\theta_{\mathrm{M}}\right)}\right)^{1.3}\right]
$$

c). After the reduced cross-section and the reduced strength of the cross-section and rebar are determined, the fire resistance calculated from the reduced columns under the room temperature is the fire resistance of the original columns subjected to fire.

Using the modified simplified approach, the reduction of the cross-sectional area and the change of temperature distribution caused by fire-induced spalling are considered. Wu et al ${ }^{[35]}$ studied explosive spalling of high strength concrete under high temperature, and proposed a regression formula of temperature difference at the central axis of a rectangular reinforced concrete column due to spalling (which was also adopted by DBJ/T 15-81). This paper adopts the same assumption that adopted by Wu et al. ${ }^{[35]}$, i.e., assumes that the concrete cover of the columns will be completely spalled out after reaching a certain heating time. Thus, the following formula is used to calculate the temperature difference due to spalling:

$$
\delta T=(466.69-0.36 t) e^{-\frac{x}{13.55+0.2 t}}(60 \min \leq t \leq 180 \mathrm{~min})
$$

In which, $x$ is the shortest distance between a point on the axis of the cross-section and the spalling surface (mm). $t$ is the heating time $(\mathrm{min}) . \delta T\left({ }^{\circ} \mathrm{C}\right)$ is the temperature difference due to spalling at distance $x$. Thus, the temperature of a point on the cross section after spalling is equal to the calculated temperature of the point without considering spalling plus the temperature difference due to spalling. The simplified approach proposed by Kodur ${ }^{[36]}$ for predicting temperature in reinforced concrete members exposed to standard fire is used here to calculate the temperature distribution on the cross section of the columns without considering spalling. It should be noted that the modified simplified approach applies only for standard fire exposure, when the fire resistance time is between 1-3 hrs and concrete spalling is limited within the concrete cover.

Using the above methods, the load bearing capacity of the precast concrete columns reinforced by efficient reinforcement in this paper is calculated. Table 4 shows the comparison between the calculated results from the above new method and the experimental results of this paper and other publications ${ }^{[7,9,37]}$. The average ratio and variation coefficient of the predictions to the experimental results are 1.09 and 0.17 , respectively. It can be seen that combining the Zone method with consideration of concrete spalling, the predicted results have good agreement with the test ones.

\begin{tabular}{|c|c|c|c|c|c|c|c|c|c|c|c|}
\hline \multirow{3}{*}{$\begin{array}{c}\text { Precast } \\
\text { Columns }\end{array}$} & \multirow{3}{*}{$\begin{array}{l}\text { Section size } \\
(\mathrm{mm} \times \mathrm{mm})\end{array}$} & \multicolumn{2}{|c|}{ Main bars } & \multicolumn{3}{|c|}{ Concrete } & \multirow{3}{*}{$\begin{array}{c}\text { End } \\
\text { conditions }\end{array}$} & \multirow{3}{*}{$\begin{array}{c}\text { Fire } \\
\text { resistance } \\
(\min )\end{array}$} & \multicolumn{3}{|c|}{ Calculated } \\
\hline & & \multirow{2}{*}{$\begin{array}{c}\text { Number \& } \\
\text { Diameter } \\
(\mathrm{mm})\end{array}$} & \multirow{2}{*}{$\begin{array}{c}\text { Yield } \\
\text { strength } \\
(\mathrm{MPa})\end{array}$} & \multirow{2}{*}{$\begin{array}{c}\text { Concrete } \\
\text { cover } \\
(\mathrm{mm})\end{array}$} & \multicolumn{2}{|c|}{$\begin{array}{c}\text { Concrete } \\
\text { Strength (MPa) }\end{array}$} & & & $\begin{array}{c}\text { Test load } \\
N_{\mathrm{t}}(\mathrm{kN})\end{array}$ & $\begin{array}{l}\text { bearing } \\
\text { capacity }\end{array}$ & $\begin{array}{l}\text { Ratio } \\
N_{\mathrm{c}} / N_{\mathrm{t}}\end{array}$ \\
\hline & & & & & $f_{\mathrm{cu}}$ & $f_{\mathrm{c}}^{\prime}$ & & & & $N_{\mathrm{c}}(\mathrm{kN})$ & \\
\hline C-B1 & $400 \times 400$ & 16 C 14 & 510 & 30 & 46.4 & - & PP & 124 & 2447 & 2703 & 1.10 \\
\hline C-B2 & $400 \times 400$ & 16 C 14 & 510 & 30 & 46.4 & - & PP & 172 & 1986 & 1896 & 0.95 \\
\hline C-M & $400 \times 400$ & 16 C 14 & 510 & 30 & 46.4 & - & FP & $>133$ & 2484 & - & - \\
\hline
\end{tabular}

Table 4 Comparison of measured and predicted bearing capacity of the precast concrete columns and

HSC columns 


\begin{tabular}{cccccccccccc} 
D-B1 & $400 \times 400$ & 4 C 28 & 464 & 50 & 46.4 & - & PP & 91 & 2447 & 2436 & 1.00 \\
D-B2 & $400 \times 400$ & 4 C 28 & 464 & 50 & 46.4 & - & PP & 140 & 1986 & 1750 & 0.88 \\
D-M & $400 \times 400$ & 4 C 28 & 464 & 50 & 46.4 & - & FP & 145 & 2484 & 1956 & 0.79 \\
HS2-4 & $406 \times 406$ & $8 C 25$ & 400 & 50 & - & 114 & FF & 146 & 4567 & 4696 & 1.03 \\
HS2-5 & $406 \times 406$ & 8 C 25 & 400 & 50 & - & 114 & FF & 108 & 5373 & 5693 & 1.06 \\
HS2-6 & $406 \times 406$ & $8 C 25$ & 400 & 50 & - & 114 & FF & 142 & 3546 & 4799 & 1.35 \\
HSC3 & $406 \times 406$ & $8 C 25$ & 414 & 48 & - & 96 & FF & 104 & 4919 & 5722 & 1.16 \\
HS4 & $406 \times 406$ & $8 \mathrm{C} 25$ & 400 & 48 & - & 89.6 & PP & 145 & 2934 & 4266 & 1.45 \\
HS6 & $406 \times 406$ & $8 \mathrm{C} 25$ & 400 & 48 & - & 96 & FF & 104 & 4919 & 5710 & 1.16 \\
\hline
\end{tabular}

$f_{\mathrm{cu}}$ and $f_{\mathrm{c}}$ ' denotes characteristic value of cubic and cylinder compressive strength of concrete, respectively.

\section{Concluding remarks}

An experimental study on the fire resistance of precast concrete columns reinforced by efficient reinforcement has been presented in this paper. A new calculation method, which considers the reduction in cross-sectional area and the temperature difference due to explosive spalling, has been proposed in combination with the use of the "Zone method" in Eurocode 2. From the experiments, comparisons and analyses of the results, the following conclusions can be drawn.

(1) The connection zone of a precast concrete columns has a higher fire resistance than that of other part of the column, and the failure always occurs first in the non-connection zone.

(2) The form of efficient reinforcement and load ratio have a marked influence on the deformations and fire resistance of precast concrete columns. When the longitudinal reinforcement ratio is the same, the fire resistance of precast concrete columns reinforced by cluster reinforcement is higher than that reinforced by large-diameter reinforcement.

(3) Fire induced spalling in concrete significantly affects thermal responses of the columns and leads to reduced fire resistance. Precast concrete columns reinforced by large-diameter reinforcement are more likely to suffer from severe concrete spalling and stirrups failure, as they normally have thicker concrete cover. It is recommended that the stirrups should be densified along the full length of the columns.

(4) The predictions from the simplified calculation methods currently in use overestimate the fire resistance of columns reinforced by efficient reinforcement, which fail to fully consider the influence of the form of the longitudinal reinforcements and the influence of concrete spalling.

(5) The new calculation method, proposed by this paper, offers improved predictions to the fire resistance of columns with efficient reinforcement.

\section{Acknowledgement}

The authors are grateful for the financial support from the National Key Research and Development Program of China (2016YFC0701402).

\section{References}


[1] G S Hou. Study on Compressive Behavior of Precast Concrete Columns with Large-diameter Rebars[D]. Shenyang Jianzhu University2018.(in Chinese)

[2] W H Liang. Experimental Study on Compressive Behavior of Precast Concrete Columns with Cluster Reinforcement[D]. Shenyang Jianzhu University2018.(in Chinese)

[3] Xu L H, Wang Q L, Yu M, et al. Experimental Study On Seismic Behavior of Cluster-Reinforced Precast Concrete Columns with Grouting-Anchor Connections[J]. Journal of Earthquake and Tsunami, 2019:1940007.

[4] Y Zhao, R Li, X Wang, et al. Experimental research on seismic behaviors of precast concrete columns with large-diameter and high-yield strength reinforcements splicing by grout-filled coupling sleeves[J]. CHINA CIVIL ENGINEERING JOURNAL, 2017(05):27-35.(in Chinese)

[5] Lie T T. Fire Resistance of Reinforced Concrete Columns: A Parametric Study[J]. Journal of Fire Protection Engineering, 1989,1(4):121-129.

[6] Dotreppe J C, Franssen J M, Bruls A, et al. Experimental Research On the Determination of the Main Parameters Affecting the Behaviour of Reinforced Concrete Columns Under Fire Conditions[J]. Magazine of Concrete Research, 1996,49(179):117-127.

[7] Kodur V, Mcgrath R. Fire Endurance of High Strength Concrete Columns[J]. Fire Technology, 2003,39(1):73-87.

[8] Kodur V K R, Cheng F P, Wang T C, et al. Effect of Strength and Fiber Reinforcement On Fire Resistance of High-Strength Concrete Columns[J]. Journal of Structural Engineering, 2003,129(2):253-259.

[9] Kodur V K R, Mcgrath R. Effect of Silica Fume and Lateral Confinement On Fire Endurance of High Strength Concrete Columns[J]. Canadian Journal of Civil Engineering, 2006,33(1):93-102.

[10] Ali F, Nadjai A, Choi S. Numerical and Experimental Investigation of the Behavior of High Strength Concrete Columns in Fire[J]. Engineering Structures, 2010,32(5):1236-1243.

[11] Ali F, Nadjai A, Silcock G, et al. Outcomes of a Major Research On Fire Resistance of Concrete Columns[J]. Fire Safety Journal, 2004,39(6):433-445.

[12] Wu B, Xu Y. Behavior of Axially-and-Rotationally Restrained Concrete Columns with '+'-Shaped Cross Section and Subjected to Fire[J]. Fire Safety Journal, 2009,44(2):212-218.

[13] Xu Y, Wu B. Fire Resistance of Reinforced Concrete Columns with L-, T-, And +-Shaped Cross-Sections[J]. Fire Safety Journal, 2009,44(6):869-880.

[14] Wu B, Li Y, Chen S. Effect of Heating and Cooling On Axially Restrained Rc Columns with SpecialShaped Cross Section[J]. Fire Technology, 2010,46(1):231-249.

[15] Tan K, Nguyen T. Structural Responses of Reinforced Concrete Columns Subjected to Uniaxial Bending and Restraint at Elevated Temperatures[J]. Fire Safety Journal, 2013,60:1-13.

[16] Tan K, Nguyen T. Experimental Behaviour of Restrained Reinforced Concrete Columns Subjected to Equal Biaxial Bending at Elevated Temperatures[J]. Engineering Structures, 2013,56(6):823-836.

[17] Rodrigues J P C, Laím L M, Korzen M. Fire Behaviour of Circular Concrete Columns with Restrained Thermal Elongation[J]. Journal of Advanced Concrete Technology, 2014,12(9):289-298.

[18] Shah A H, Sharma U K. Fire Resistance and Spalling Performance of Confined Concrete Columns[J]. Construction and Building Materials, 2017,156:161-174.

[19] Rush D, Lange D. Towards a Fragility Assessment of a Concrete Column Exposed to a Real Fire - Tisova Fire Test[J]. Engineering Structures, 2017,150:537-549.

[20] Buch S H, Sharma U K. Fire Resistance of Eccentrically Loaded Reinforced Concrete Columns[J]. Fire Technology, 2019,55(5):1517-1552.

[21] Martins A M B, Rodrigues J P C. Fire Resistance of Reinforced Concrete Columns with Elastically Restrained Thermal Elongation[J]. Engineering Structures, 2010,32(10):3330-3337.

[22] Park J E, Shin Y S, Kim H S. Various Factors Influencing On Thermal Behaviors of High Strength Concrete 
(Hsc) Columns Under Fire[J]. Procedia Engineering, 2011,14:427-433.

[23] Raut N K, Kodur V K R. Response of High-Strength Concrete Columns Under Design Fire Exposure[J]. Journal of Structural Engineering, 2011,137(1):69-79.

[24] Zhang W, Deng X, Zhang J, et al. Tensile Behavior of Half Grouted Sleeve Connection at Elevated Temperatures[J]. Construction and Building Materials, 2018,176:259-270.

[25] Zhang W, He C, Zhang J, et al. Mechanical Behavior of Post-Fire Half-Grouted Sleeve Connection Covered by Concrete[J]. Construction and Building Materials, 2019,201:218-231.

[26] Eurocode 2: Design of Concrete Structures-Part 1-2:General Rules-Structural Fire Design[S]. Brussels: CEN, 2004.

[27] DBJ/T 15-81-2011. Code for Fire Resistance Design of Concrete Structures in Buildings[S]. China Architecture\& Building Press, 2011. (in Chinese)

[28] Wu B, Hong Z, Tang G H, et al. Fire Resistance of Reinforced Concrete Columns with Square Cross Section[J]. Advances in Structural Engineering, 2007.

[29] Kodur V, Raut N. A Simplified Approach for Predicting Fire Resistance of Reinforced Concrete Columns Under Biaxial Bending[J]. Engineering Structures, 2012,41(3):428-443.

[30] GB 50010-2010. Code for Design of Concrete Structures[S]. China Architecture\& Building Press, 2010. (in Chinese)

[31] GB/T 51231-2016. Technical Standard for Assembled Buildings with Concrete Structure[S]. China Architecture\& Building Press, 2017. (in Chinese)

[32] Mao X, Kodur V K R. Fire Resistance of Concrete Encased Steel Columns Under 3- And 4-Side Standard Heating[J]. Journal of Constructional Steel Research, 2011,67(3):270-280.

[33] GB/T 9978-2008. Fire-Resistance Tests-Elements of Building Construction[S]. China Architecture\& Building Press, 2008. (in Chinese)

[34] ISO 834-1: Fire-Resistance Tests—Elements of Building Construction—Part 1: General Requirements[S]. International Organization for Standardization, 1999.

[35] B Wu, J Yuan, H Li, et al. Explosive spalling rules of high strength concrete under high temperature and calculation for temperature field of column cross section[J]. JOURNAL OF NATURAL DISASTERS, 2002(02):65-69.(in Chinese)

[36] Kodur V K R, Yu B, Dwaikat M M S. A Simplified Approach for Predicting Temperature in Reinforced Concrete Members Exposed to Standard Fire[J]. Fire Safety Journal, 2013,56:39-51.

[37] Kodur V K R, Mcgrath R C, Latour J C, et al. Experimental Studies On the Fire Endurance of High-Strength Concrete Columns, Internal Report 819[R].National Research Council, 2000. 